\title{
A Theoretical Study of the Wet Removal of Atmospheric Pollutants. Part IV: The Uptake and Redistribution of Aerosol Particles through Nucleation and Impaction Scavenging by Growing Cloud Drops and Ice Particles
}

\author{
R. R. Alheit,* A. I. Flossmann and H. R. PrupPacher \\ Meteorological Institute, Joh. Gutenberg University, Mainz, Federal Republic of Germany
}

(Manuscript received 27 March 1989, in final form 16 October 1989)

\begin{abstract}
A theoretical model has been formulated which allows the study of the effects of an ice phase on the removal of atmospheric aerosol particles by nucleation and impaction scavenging in a convective cloud. This microphysical model-although in principle applicable to higher dimensional cloud dynamic models-was tested by using a simple parcel model with entrainment as the dynamic framework. The present model has been applied to and numerically evaluated for a convective cloud in which the cloud particles grow via vapor deposition, collision, and coalescence and riming. The computations were carried out for a rural-background aerosol of given particle size distribution. Two different chemical compositions of the aerosol particles and two different modes of ice initiation were considered. Our study shows for in-cloud scavenging: (i) scavenging of aerosol particles by drop nucleation dominates impaction scavenging by drops as well as all other scavenging mechanisms; (ii) scavenging of aerosol particles by nucleation of snow crystals via drop freezing or any other nucleation mechanism dominates impaction scavenging by snow crystals; (iii) impaction scavenging of aerosol particles by snow crystals is, for the conditions studied, the least efficient scavenging mechanism; (iv) scavenging of aerosol particles by riming of graupel is an extremely efficient process due to the prominent scavenging of aerosol particles by nucleation of drops and the efficient uptake of drops by graupel; $(v)$ the transfer of aerosol mass into the ice phase by riming of graupel and by freezing of drops dominates all other transfer mechanisms, (vi) inside mixed icewater clouds the aerosol mass becomes redistributed in such a manner that the main aerosol mass is associated with the main graupel mass if riming is the dominant process of precipitation formation, and with the main water mass if collision and coalescence of drops in the dominant process of precipitation formation.
\end{abstract}

\section{Introduction}

In three recent publications (Flossmann et al. 1985, 1987; Flossmann and Pruppacher 1988) we have attempted to shed some light on the removal mechanisms of particulate and gaseous atmospheric sulfur by convective clouds and precipitation. In our first two studies (Flossmann et al. 1985, 1987) we have used our air parcel model with detailed microphysics. From sensitivity studies we were able to point out some interesting facts on the redistribution of the particulate and gaseous pollutants inside a cloud, on the significance of particle removal by nucleation scavenging, and on the relative efficiency with which sulfate aerosol particles and $\mathrm{SO}_{2}$ gas become incorporated in the cloud water depending on various parameters. In a subsequent study (Flossmann and Pruppacher 1988) we have coupled our particle scavenging model with the two-dimensional model for convective clouds by Clark and coworkers (Clark 1977, 1979; Clark and Gall 1982; Clark and Farley

* Part of a Ph.D. thesis.

Corresponding author address: Dr. H. R. Pruppacher, Institut fur Meteorologie, Johannes Gutenberg Universitat, Mainz, Postfach 3980, D-6500 Mainz, Federal Republic of Germany.
1984; and Hall 1980) and applied this model to a specific case in Hawaii.

All three model studies assumed that the clouds under investigation consisted entirely of liquid water, and that no ice phase was present. Most midlatitude clouds, however, contain ice particles. Thus the question arises as to how the ice phase affects the uptake, the redistribution inside the cloud, and the deposition of the pollutants. We, therefore, consider in the present paper the uptake and redistribution of aerosol particles inside a mixed ice-water cloud.

Considerable knowledge is available in literature which documents the capability of snow crystals to scavenge aerosol particles either by direct pick-up or indirectly by colliding with cloud drops which contain scavenged aerosol particles. Thus, field measurements to this effect have been carried out by Magono et al. (1974), Graedel and Franey (1975), Magono et al. (1975a,b), Magono et al. (1979), Scott (1981), Delmas et al. (1982), Borys et al. (1983), Mayewski and Lyons (1983), Murakami et al. (1983), Raynor and Hayes (1983), and Borys et al. (1988). Laboratory studies which determined the scavenging efficiency of aerosol particles by ice crystals were carried out by Starr and Mason (1966), Vittori and Prodi (1967), Sood and Jackson (1970), Stavitskaya (1972), Vittori (1973), 
Knutson et al. (1976), Murakami et al. (1981), Prodi et al. (1981), Prodi (1983), Murakami and Magono (1983), Murakami et al. (1985), and Sauter and Wang (1989). Theoretical studies which attempted to determine the aerosol particle scavenging efficiency of ice crystals were performed by Martin et al. (1980), Wang and Pruppacher (1980), Wang and Chuang (1983), and Wang (1985).

Up to now several theoretical studies have been performed using models which have been formulated for mixed phase ice-water clouds to determine the rate at which these clouds take up aerosol particles and gaseous pollutants (Scott 1982a,b; Easter and Hales 1983; Molenkamp 1983; Hegg et al. 1984; Rutledge et al. 1986). However, in all of these models some form of bulk parameterization was used to describe the microphysical processes. This did not allow following the uptake and redistribution of the scavenged pollutants as the drop and ice particle size distributions evolve.

The present study attempts to broaden the results obtained by the above mentioned bulk parameterized models with the results from our own spectral model which we extended to mixed ice-water clouds. However, the complex nature of the mixed ice-water clouds prevented us from considering all microphysical processes involved in such clouds. Thus, we considered, as a first step, a simple convective cloud in which drops and snow crystals were nucleated, and then grew by diffusion of water vapor. Subsequently, the drops were growing by collision and coalescence and the snow crystals by riming. Aggregation of snow crystals and splintering mechanisms were not considered in this first step of model performance. We also confined ourselves to the in-cloud scavenging processes. The effects of fallout of precipitation particles, and the effects of belowcloud scavenging were not considered. Although these restrictions limit the applicability of our results we, nevertheless, were able to deduce from our model some results of general applicability, such as to determine (1) the relative importance of aerosol particle scavenging via ice nucleation as compared to the uptake of aerosol particles by snow crystals via impaction scavenging, (2) the relative importance of the uptake of aerosol particles by snow crystals as compared to the uptake by drops, ( 3 ) the relative importance of the uptake of aerosol particles by snow crystals and graupel via riming as compared to other uptake mechanisms, and (4) the effects of the presence of the ice phase on the redistribution of the scavenged aerosol particles inside the cloud.

\section{The present model}

\section{a. General}

For the present study on the in-cloud scavenging of aerosol particles by drops and ice particles we used the air parcel model of Flossmann et al. (1985) which was extended to a mixed phase ice-water cloud. This model allows entrainment of air and gives a detailed descrip- tion of many pertinent cloud microphysical processes. At present the model includes: the nucleation of drops and snow crystals, their growth by diffusion of water vapor, the growth of the drops by collision and coalescence, the breakup of drops, the growth of the snow crystals by riming, and the growth of the graupel by diffusion of water vapor and riming. Below-cloud scavenging and the effects of ice particle melting and aggregation will be considered at a later time in our two-dimensional cloud model with spectral microphysics previously applied to warm clouds (Flossmann and Pruppacher 1988). This work is presently in preparation. Furthermore, the present model makes the assumption that ice nucleation proceeds foremostly in the temperature range $-10^{\circ}$ to $-20^{\circ} \mathrm{C}$ where planar type snow crystals are nucleated. Alternatively, ice particles were assumed to result from drop freezing. After nucleation, both ice particles were assumed to grow by vapor diffusion and riming. Field observations support the assumption that in convective type clouds most graupel appear to have originated on planar snow crystals or frozen drops rather than on columnar or needle crystals.

\section{b. Specifics}

A complete list of all equations necessary to describe the model would go beyond the allowed length of a paper. Thus, we decided to discuss only those equations which are new. For all other equations we shall refer to our previous article (Flossmann et al. 1985). For the nomenclature used we refer to the list of symbols given in the Appendix of this paper.

The time rate of change of the cloud drop number density distribution function, $f_{d}$, is given by the relation

$$
\begin{aligned}
& \frac{\partial f_{d}(m)}{\partial t}=-\mu f_{d}(m) U+\left.\frac{\partial f_{d}(m)}{\partial t}\right|_{d, \text { coal }} \\
& +\left.\frac{\partial f_{d}(m)}{\partial t}\right|_{\text {AP,coll }, d}+\left.\frac{\partial f_{d}(m)}{\partial t}\right|_{\text {con } / \mathrm{eva}}+\left.\frac{\partial f_{d}(m)}{\partial t}\right|_{\text {act }} \\
& +\left.\frac{\partial f_{d}(m)}{\partial t}\right|_{d, \text { break }}+\left.\frac{\partial f_{d}(m)}{\partial t}\right|_{i, \text { rim }} \\
& +\left.\frac{\partial f_{d}(m)}{\partial t}\right|_{g, \text { rim }}+\left.\frac{\partial f_{d}(m)}{\partial t}\right|_{\text {frd }} .
\end{aligned}
$$

Term 1 on the right-hand side of Eq. (1) is the entrainment term, the terms 2 to 5 are given by Eqs. (5), (10)-(11), (13) and (15), and (19)-(21), respectively, in Flossmann et al. (1985). Term 6 was evaluated after Hall (1980). The last three terms are new and are given by the equations

$$
\left.\frac{\partial f_{d}(m)}{\partial t}\right|_{i, \mathrm{rim}}=-f_{d}(m) \int_{0}^{\infty} f_{i}\left(a_{i}\right) K_{i}\left(a_{i}, a(m)\right) d a_{i}
$$


$\left.\frac{\partial f_{d}(m)}{\partial t}\right|_{g, \text { rim }}=-f_{d}(m) \int_{0}^{\infty} f_{g}\left(a_{g}\right) K_{g}\left(a_{g}, a(m)\right) d a_{g}$

$$
\left.\frac{\partial f_{d}(m)}{\partial t}\right|_{\text {frd }}=-f_{d}(m) B^{\prime} \frac{m}{\rho_{w}} \exp \left(b^{\prime}\left(T_{o}-T\right)\right) .
$$

The time rate of change of the mass density distribution function of aerosol particle mass in the drops, $g_{\mathrm{AP} d}$, is given by the relation

$$
\begin{aligned}
& \frac{\partial g_{\mathrm{AP} d}(m)}{\partial t}=-\mu g_{\mathrm{AP} d}^{\prime}(m) U+\left.\frac{\partial g_{\mathrm{AP} d}(m)}{\partial t}\right|_{d, \text { coal }} \\
& \quad+\left.\frac{\partial g_{\mathrm{AP} d}(m)}{\partial t}\right|_{\mathrm{AP}, \mathrm{coll}, d}+\left.\frac{\partial g_{\mathrm{AP} d}(m)}{\partial t}\right|_{\mathrm{con} / \mathrm{eva}} \\
& \quad+\left.\frac{\partial g_{\mathrm{AP} d}(m)}{\partial t}\right|_{\mathrm{act}}+\left.\frac{\partial g_{\mathrm{AP} d}(m)}{\partial t}\right|_{d, \text { break }} \\
& \quad+\left.\frac{\partial g_{\mathrm{AP} d}(m)}{\partial t}\right|_{i, \text { rim }}+\left.\frac{\partial g_{\mathrm{APd} d}(m)}{\partial t}\right|_{g, \text { rim }}+\left.\frac{\partial g_{\mathrm{AP} d}(m)}{\partial t}\right|_{\text {frd }}
\end{aligned}
$$

Term 1 on the right-hand side of Eq. ( 5 ) is the entrainment term, the terms 2 to 5 are given by Eqs. (6)-(7), (12) and (14), and (19)-(21), respectively, in Flossmann et al. (1985). Again, term 6 was evaluated after Hall (1980). The last three terms are new and are given by the equations

$$
\left.\frac{\partial g_{\mathrm{APd} d}(m)}{\partial t}\right|_{i, \mathrm{rim}}=-g_{\mathrm{APd}}(m) \int_{0}^{\infty} f_{i}\left(a_{i}\right) K_{i}\left(a_{i}, a(m)\right) d a_{i}
$$

$$
\begin{aligned}
\left.\frac{\partial g_{\mathrm{AP} d}(m)}{\partial t}\right|_{g, \mathrm{rim}}= & -g_{\mathrm{APd}}(m) \\
& \times \int_{0}^{\infty} f_{g}\left(a_{g}\right) K_{g}\left(a_{g}, a(m)\right) d a_{g}
\end{aligned}
$$

$\left.\frac{\partial g_{\mathrm{APd}}(m)}{\partial t}\right|_{\mathrm{frd}}=-g_{\mathrm{APd}}(m) B^{\prime} \frac{m}{\rho_{w}} \exp \left(b^{\prime}\left(T_{o}-T\right)\right)$

with

$$
\begin{gathered}
K_{i}\left(a_{i}, a\right)=\pi E_{i}\left(a_{i}, a\right)\left(a_{i}+a\right)^{2}\left|u_{i, \infty}\left(a_{i}\right)-u_{d, \infty}(a)\right| \\
K_{g}\left(a_{g}, a\right)=\pi E_{g}\left(a_{g}, a\right)\left(a_{g}+a\right)^{2} \\
\quad \times\left|u_{g, \infty}\left(a_{g}\right)-u_{d, \infty}(a)\right| .
\end{gathered}
$$

In Eq. (10) $E_{g}\left(a_{g}, a\right)$ was computed after Hall (1980) and Rasmussen and Heymsfield (1985) who replaced in the scheme of Beard and Grover (1974) the Stokes inertia parameter by the mixed Froud number for the case that $40 \mu \mathrm{m} \leqslant a_{g} \leqslant 600 \mu \mathrm{m}$, and that $a / a_{g} \leqslant 0.1$.
For all other combinations the collision efficiencies summarized by Hall (1980) were used. For $u_{g, \infty}\left(a_{g}\right)$ we used the terminal velocities for lump graupel III given by Locatelli and Hobbs (1974). The fall speeds of the drops $u_{d, \infty}(a)$ were computed following the scheme of Beard (1976). The collision efficiencies $E_{i}\left(a_{i}, a\right)$ of snow-crystal plates colliding with drops in Eq. (9) were those given by Martin et al. (1981), and the terminal velocities of unrimed and rimed snow crystals were those of Heymsfield (1972) and Locatelli and Hobbs (1974), respectively.

The time rate of change of the number density distribution function for aerosol particles remaining in the air, $f_{\mathrm{APa} a}$, is given by the relation

$$
\begin{gathered}
\frac{\partial f_{\mathrm{APa} a}\left(m_{\mathrm{AP}}\right)}{\partial t}=-\mu\left(f_{\mathrm{AP} a}\left(m_{\mathrm{AP}}\right)-f_{\mathrm{AP} a}^{\prime}\left(m_{\mathrm{AP}}\right)\right) U \\
+\left.\frac{\partial f_{\mathrm{AP} a}\left(m_{\mathrm{AP}}\right)}{\partial t}\right|_{\mathrm{con} / \mathrm{eva}}+\left.\frac{\partial f_{\mathrm{APa} a}\left(m_{\mathrm{AP}}\right)}{\partial t}\right|_{\mathrm{AP}, \mathrm{coll}, d} \\
+\left.\frac{\partial f_{\mathrm{APa} a}\left(m_{\mathrm{AP}}\right)}{\partial t}\right|_{\mathrm{act}}+\left.\frac{\partial f_{\mathrm{APa} a}\left(m_{\mathrm{AP}}\right)}{\partial t}\right|_{\mathrm{AP}, \text { coll }, i} \\
+\left.\frac{\partial f_{\mathrm{AP} a}\left(m_{\mathrm{AP}}\right)}{\partial t}\right|_{\mathrm{AP}, \text { coll }, g}
\end{gathered}
$$

Term 1 on the right-hand side of Eq. (11) again is the entrainment term; the terms 2 to 4 are given by Eqs. (8), (16) and (18), and (19)-(21), respectively, in Flossmann et al. (1985). The last two terms are new and given by the equations

$$
\begin{aligned}
& \left.\frac{\partial f_{\mathrm{APa} a}\left(m_{\mathrm{AP}}\right)}{\partial t}\right|_{\mathrm{AP}, \text { coll }, i}=-f_{\mathrm{AP} a}\left(m_{\mathrm{AP}}\right) \\
& \quad \times \int_{0}^{\infty} f_{i}\left(a_{i}\right) K_{i, A P}\left(a_{i}, r_{\mathrm{AP}}\left(m_{\mathrm{AP}}\right)\right) d a_{i} \\
& \left.\frac{\partial f_{\mathrm{AP} a}\left(m_{\mathrm{AP}}\right)}{\partial t}\right|_{\mathrm{AP}, \text { coll }, g}=-f_{\mathrm{AP} a}\left(m_{\mathrm{AP}}\right) \\
& \times \int_{0}^{\infty} f_{g}\left(a_{g}\right) K_{g, \mathrm{AP}}\left(a_{g}, r_{\mathrm{AP}}\left(m_{\mathrm{AP}}\right)\right) d a_{g}
\end{aligned}
$$

in which

$$
K_{i, \mathrm{AP}}\left(a_{i}, r_{\mathrm{AP}}\right)=\pi E_{i, \mathrm{AP}}\left(a_{i}, r_{\mathrm{AP}}\right)\left(a_{i}+r_{\mathrm{AP}}\right)^{2} u_{i, \infty}\left(a_{i}\right)
$$

$K_{g, \mathrm{AP}}\left(a_{g}, r_{\mathrm{AP}}\right)=\pi E_{g, \mathrm{AP}}\left(a_{g}, r_{\mathrm{AP}}\right)\left(a_{g}+r_{\mathrm{AP}}\right)^{2} u_{g, \infty}\left(a_{g}\right)$.

The efficiencies $E_{i, \mathrm{AP}}\left(a_{i}, r_{\mathrm{AP}}\right)$ for the collision of snow crystals with aerosol particles were taken from the theoretical values of Martin et al. (1980) for a water saturated environment supplemented by the experimental values of Murakami et al. (1985). The efficiencies for the collision of graupel particles with aerosol particles were computed on the assumption $E_{g, \mathrm{AP}}\left(a_{g}, r_{\mathrm{AP}}\right)=E_{d, \mathrm{AP}}\left(a=a_{g}, r_{\mathrm{AP}}\right)$. Values for $E_{d, \mathrm{AP}}(a$, 
$r_{\mathrm{AP}}$ ) were derived from a combination of the theoretically computed values of Grover et al. (1977) with the experimental values of Wang et al. (1978), as used in our earlier computations (Flossmann et al., 1985).

The time rate of change of the mass density distribution function for the aerosol particle mass remaining in the air, $g_{\mathrm{APa} a}$, is given by the relation

$$
\begin{gathered}
\frac{\partial g_{\mathrm{AP} a}\left(m_{\mathrm{AP}}\right)}{\partial t}=-\mu\left(g_{\mathrm{AP} a}\left(m_{\mathrm{AP}}\right)-g_{\mathrm{APa}}^{\prime}\left(m_{\mathrm{AP}}\right)\right) U \\
+\left.\frac{\partial g_{\mathrm{AP} a}\left(m_{\mathrm{AP}}\right)}{\partial t}\right|_{\mathrm{con} / \mathrm{eva}}+\left.\frac{\partial g_{\mathrm{APa} a}\left(m_{\mathrm{AP}}\right)}{\partial t}\right|_{\mathrm{AP}, \text { coll }, d} \\
+\left.\frac{\partial g_{\mathrm{AP} a}\left(m_{\mathrm{AP}}\right)}{\partial t}\right|_{\mathrm{act}}+\left.\frac{\partial g_{\mathrm{AP} a}\left(m_{\mathrm{AP}}\right)}{\partial t}\right|_{\mathrm{AP}, \text { coll }, i} \\
+\left.\frac{\partial g_{\mathrm{APa} a}\left(m_{\mathrm{AP}}\right)}{\partial t}\right|_{\mathrm{AP}, \text { coll }, g}
\end{gathered}
$$

Term 1 on the right-hand side of Eq. (16) again is the entrainment term; the terms 2 to 4 are given by Eqs. (9), (17) and (18), and (19)-(21), respectively, in Flossmann et al. (1985). The last two terms are new and are given by the equations

$$
\begin{aligned}
& \left.\frac{\partial g_{\mathrm{APa} a}\left(m_{\mathrm{AP}}\right)}{\partial t}\right|_{\mathrm{AP}, \mathrm{coll}, i}=-g_{\mathrm{APa} a}\left(m_{\mathrm{AP}}\right) \\
& \quad \times \int_{0}^{\infty} f_{i}\left(a_{i}\right) K_{i, \mathrm{AP}}\left(a_{i}, r_{\mathrm{AP}}\left(m_{\mathrm{AP}}\right)\right) d a_{i} \\
& \left.\frac{\partial g_{\mathrm{AP} a}\left(m_{\mathrm{AP}}\right)}{\partial t}\right|_{\mathrm{AP}, \text { coll }, g}=-g_{\mathrm{APa}}\left(m_{\mathrm{AP}}\right) \\
& \times \int_{0}^{\infty} f_{g}\left(a_{g}\right) K_{g, \mathrm{AP}}\left(a_{g}, r_{\mathrm{AP}}\left(m_{\mathrm{AP}}\right)\right) d a_{g} .
\end{aligned}
$$

The time rate of change of the number density distribution function for snow crystals, which describes the size distribution of the snow crystals, can be expressed in a form analogous to the function for drops

$$
\begin{aligned}
\frac{\partial f_{i}\left(a_{i}\right)}{\partial t} & =-\mu f_{i}\left(a_{i}\right) U+\left.\frac{\partial f_{i}\left(a_{i}\right)}{\partial t}\right|_{\text {act }} \\
+ & +\left.\frac{\partial f_{i}\left(a_{i}\right)}{\partial t}\right|_{\text {frd }}+\left.\frac{\partial f_{i}\left(a_{i}\right)}{\partial t}\right|_{\text {dep }}+\left.\frac{\partial f_{i}\left(a_{i}\right)}{\partial t}\right|_{\text {conv }} .
\end{aligned}
$$

The time rate of change of the mass density distribution function for snow crystals is given by

$$
\begin{aligned}
\frac{\partial g_{i}\left(a_{i}\right)}{\partial t}= & -\mu g_{i}\left(a_{i}\right) U+\left.\frac{\partial g_{i}\left(a_{i}\right)}{\partial t}\right|_{\text {act }}+\left.\frac{\partial g_{i}\left(a_{i}\right)}{\partial t}\right|_{\mathrm{frd}} \\
& +\left.\frac{\partial g_{i}\left(a_{i}\right)}{\partial t}\right|_{\mathrm{dep}}+\left.\frac{\partial g_{i}\left(a_{i}\right)}{\partial t}\right|_{\mathrm{conv}} \\
& +\left.\frac{\partial g_{i}\left(a_{i}\right)}{\partial t}\right|_{\mathrm{AP}, \mathrm{coll}, i}+\left.\frac{\partial g_{i}\left(a_{i}\right)}{\partial t}\right|_{i, \mathrm{rim}} .
\end{aligned}
$$

The time rate of change of the mass density distribution function of aerosol particle mass in the snow crystals is given by

$$
\begin{aligned}
& \frac{\partial g_{\mathrm{AP} i}\left(a_{i}\right)}{\partial t}=-\mu g_{\mathrm{AP} i}\left(a_{i}\right) U+\left.\frac{\partial g_{\mathrm{AP} i}\left(a_{i}\right)}{\partial t}\right|_{\mathrm{act}} \\
&+\left.\frac{\partial g_{\mathrm{AP} i}\left(a_{i}\right)}{\partial t}\right|_{\mathrm{frd}}+\left.\frac{\partial g_{\mathrm{AP} i}\left(a_{i}\right)}{\partial t}\right|_{\mathrm{dep}}+\left.\frac{\partial g_{\mathrm{AP} i}\left(a_{i}\right)}{\partial t}\right|_{\mathrm{conv}} \\
&+\left.\frac{\partial g_{\mathrm{AP} i}\left(a_{i}\right)}{\partial t}\right|_{\mathrm{AP}, \mathrm{coll}, i}+\left.\frac{\partial g_{\mathrm{AP} i}\left(a_{i}\right)}{\partial t}\right|_{i, \mathrm{rim}}
\end{aligned}
$$

The number density distribution function for graupel, $f_{g}$, is written as

$$
\begin{aligned}
\frac{\partial f_{g}\left(a_{g}\right)}{\partial t}= & -\mu f_{g}\left(a_{g}\right) U+\left.\frac{\partial f_{g}\left(a_{g}\right)}{\partial t}\right|_{\text {frd }} \\
& +\left.\frac{\partial f_{g}\left(a_{g}\right)}{\partial t}\right|_{\text {dep }}+\left.\frac{\partial f_{g}\left(a_{g}\right)}{\partial t}\right|_{\text {conv }} \\
& +\left.\frac{\partial f_{g}\left(a_{g}\right)}{\partial t}\right|_{\mathrm{AP}, \text { coll }, g}+\left.\frac{\partial f_{g}\left(a_{g}\right)}{\partial t}\right|_{g, \text { rim }} .
\end{aligned}
$$

The time rate of change of the mass density distribution function for graupel, $g_{g}$, is given by

$$
\begin{gathered}
\frac{\partial g_{g}\left(a_{g}\right)}{\partial t}=-\mu g_{g}\left(a_{g}\right) U+\left.\frac{\partial g_{g}\left(a_{g}\right)}{\partial t}\right|_{\text {frd }}+\left.\frac{\partial g_{g}\left(a_{g}\right)}{\partial t}\right|_{\text {dep }} \\
\quad+\left.\frac{\partial g_{g}\left(a_{g}\right)}{\partial t}\right|_{\text {conv }}+\left.\frac{\partial g_{g}\left(a_{g}\right)}{\partial t}\right|_{\text {AP,coll, }, g}+\left.\frac{\partial g_{g}\left(a_{g}\right)}{\partial t}\right|_{g, \text { rim }} .
\end{gathered}
$$

The corresponding time rate of change of the mass density distribution function of aerosol particle mass in the graupel, $g_{\mathrm{APg}}$, is

$$
\begin{aligned}
\frac{\partial g_{\mathrm{AP} g}\left(a_{g}\right)}{\partial t}= & -\mu g_{\mathrm{APg}}\left(a_{g}\right) U+\left.\frac{\partial g_{\mathrm{APg}}\left(a_{g}\right)}{\partial t}\right|_{\mathrm{frd}} \\
& +\left.\frac{\partial g_{\mathrm{AP} g}\left(a_{g}\right)}{\partial t}\right|_{\mathrm{dep}}+\left.\frac{\partial g_{\mathrm{AP} g}\left(a_{g}\right)}{\partial t}\right|_{\mathrm{conv}} \\
& +\left.\frac{\partial g_{\mathrm{APg}}\left(a_{g}\right)}{\partial t}\right|_{\mathrm{AP}, \text { coll }, g}+\left.\frac{\partial g_{\mathrm{APg}}\left(a_{g}\right)}{\partial t}\right|_{g, \text { rim }}
\end{aligned}
$$

The first term on the right-hand side of Eqs. (19) to (24) expresses the effects of entrainment. In the following we shall discuss briefly each of the remaining terms. Actually, on the right-hand side of Eq. (19) one would expect the additional term $\left.\left\{\left[\partial f_{i}\left(a_{i}\right)\right] / \partial t\right\}\right|_{i, \text { rim }}$ to describe the time rate of change of the number density distribution function of snow crystals due to riming. However, this term is neglected since we assume that the attached drops are uniformly distributed on the basal face of the snow crystal and therefore do not con- 
tribute to the growth of the snow crystal along the $a$ axis, i.e., a change of the number density distribution function. This assumption is justified as studies [e.g. by Pflaum et al. (1978) and Lew et al. (1986a,b)] have shown that riming of crystals contributes most to the basal faces of the crystal plates. Riming and impaction scavenging, however, contribute to the time rate of change of the mass density distribution functions of snow crystals and aerosol particle mass in snow crystals, $g_{i}$ and $g_{\mathrm{AP} i}$, respectively.

The second term on the right-hand side of Eq. (19) can be computed by assuming a certain mechanism for ice nucleation. In our model nucleation of snow crystals was assumed to proceed either by means of drop freezing or by nucleation of snow crystals from the vapor. In the latter case the formulation of Heymsfield et al. (1979) was used

$$
N_{I N}\left(m^{-3}\right)=130\left(\frac{T_{o}-T}{16}\right)^{3 / 2}
$$

with $T_{o}=273.15 \mathrm{~K}$, based on measurements in Colorado cumulus congestus. This equation was assumed to hold up to almost $0^{\circ} \mathrm{C}$.

Another relationship for the dependence of the snow crystal concentration on temperature and broadness of the droplet distribution has been given by Hobbs and Rangno (1985) for clouds in the Pacific North West area. They found, that in most of the observed convective clouds with top temperatures $\leqslant-6^{\circ} \mathrm{C}$ the maximum ice particle concentrations had values of roughly $0.1 \%$ of the values of the total number concentration of drops larger than $20 \mu \mathrm{m}$ in diameter. Since this relationship-when used in our model-gave values for the maximum ice particle concentrations which were in between those computed from Eq. (25) and Eq. (29) for drop freezing, we did not include in this report our results with the Hobbs-Rangno relationship.

The change in time of the snow crystal number concentration function due to nucleation of snow crystals from the vapor then is given by

$$
\left.\frac{\partial f_{i}\left(a_{i}\right)}{\partial t}\right|_{\text {act }}=\frac{N_{I N}-\left(N_{i}+N_{g}\right)}{\Delta t}
$$

where $\Delta t$ is the time step in the numerical computation. From Eq. (26) the corresponding change of the aerosol particle mass in the snow crystals was computed from

$$
\left.\frac{\partial g_{\mathrm{APi}}\left(a_{i}\right)}{\partial t}\right|_{\mathrm{act}}=\left.\frac{\partial f_{i}\left(a_{i}\right)}{\partial t}\right|_{\mathrm{act}} m_{I N}
$$

For simplicity it was assumed that the aerosol particles, on which ice nucleation from the vapor occurred, had a typical radius of $1 \mu \mathrm{m}$ and a density of $2 \mathrm{~g} \mathrm{~cm}^{-3}$. Such a value is justified considering the field observations of Rosinski et al. (1980) and of Stein and Georgii
(1983). The corresponding change of the mass density distribution function for snow crystals was computed from

$$
\left.\frac{\partial g_{i}\left(a_{i}\right)}{\partial t}\right|_{\text {act }}=\left.\frac{\partial f_{i}\left(a_{i}\right)}{\partial t}\right|_{\text {act }} m_{i}\left(a_{i}\right)
$$

where $m_{i}$ is the mass of the planar snow crystal.

When ice nucleation was considered to proceed via drop freezing the change in the number and mass distribution functions of snow crystals and graupel were computed from the formula of Bigg (1.953) (see also Pruppacher and Klett 1978, 274-281):

$$
\frac{d N_{f}}{d t}=N_{d} B^{\prime} V_{d} \exp \left[b^{\prime}\left(T_{o}-T\right)\right]
$$

where $N_{f}$ is the number of frozen drops and $N_{d}$ is the number of unfrozen drops of volume $V_{d}$, and with $B^{\prime}$ $=10^{-4} \mathrm{~cm}^{-3} \mathrm{sec}^{-1}$ and $b^{\prime}=0.66$ after a suggestion of Orville and Kopp (1977).

For computing the change in the mass-density distribution function of aerosol particle mass in the frozen drops we assumed that the aerosol mass captured by the drop prior to freezing was incorporated into the resulting ice particles. In addition, we arbitrarily assigned all frozen drops with radii smaller than $100 \mu \mathrm{m}$ to the category of snow crystals and assumed that they would continue to grow into hexagonal plate-like snow crystals (see Pruppacher and Klett 1978, Fig. 16-4). Drops with radii larger than $100 \mu \mathrm{m}$ we arbitrarily assigned to the category of graupel. With this working hypothesis we were able to compute the change in the number and mass distribution functions for graupel and snow crystals due to drop freezing $\partial f_{g}\left(a_{g}\right) /\left.\partial t\right|_{\text {frd }}$, $\partial f_{i}\left(a_{i}\right) /\left.\partial t\right|_{\text {frd }}, \partial g_{g}\left(a_{g}\right) /\left.\partial t\right|_{\text {frd }}$ and $\partial g_{i}\left(a_{i}\right) /\left.\partial t\right|_{\text {frd }}$, respectively, and the change in the mass distribution function of the aerosol particle mass in the graupel and snow crystals, $\partial g_{\mathrm{APg}}\left(a_{g}\right) /\left.\partial t\right|_{\text {frd }}$ and $\partial g_{\mathrm{AP} i}\left(a_{i}\right) /\left.\partial t\right|_{\text {frd }}$, respectively.

The growth of snow crystals by vapor deposition was computed from

$$
\begin{aligned}
\left.\frac{d m_{i}\left(a_{i}\right)}{d t}\right|_{\text {dep }}= & {\left[4 \pi C^{*}\left(a_{i}\right) s_{v / i}(T) f_{v, L^{*}}\right] / } \\
& {\left[\frac{L_{s}}{k_{a} T}\left(\frac{L_{s}}{R_{v} T}-1\right)+\frac{1}{D_{v}^{*} \rho_{\mathrm{sat}, i}(T)}\right] }
\end{aligned}
$$

where

$$
f_{v, L^{*}}= \begin{cases}1.00+0.14 \chi^{2}, & \chi<1.0 \\ 0.86+0.28 \chi^{2}, & \chi \geqslant 1.0\end{cases}
$$

and where the shape factor $C^{*}$ was computed according to Pruppacher and Klett [1978, Eqs. (13-71) and (1387)]. With Eq. (30) it was possible to compute the effect of vapor deposition on the time rate of change of the number and mass density distribution functions for snow crystals, and on the time rate of change of 
the mass density distribution function of aerosol particle mass in the snow crystals from

$$
\begin{aligned}
&\left.\frac{\partial f_{i}\left(a_{i}\right)}{\partial t}\right|_{\text {dep }}=-\frac{\partial}{\partial \ln a_{i}}\left\{\left.\frac{d \ln a_{i}}{d t}\right|_{\text {dep }} f_{i}\left(a_{i}\right)\right\} \\
&\left.\frac{\partial g_{i}\left(a_{i}\right)}{\partial t}\right|_{\text {dep }}=\left.f_{i}\left(a_{i}\right) \frac{d m_{i}\left(a_{i}\right)}{d t}\right|_{\text {dep }} \\
&-\frac{\partial}{\partial \ln a_{i}}\left\{\left.\frac{d \ln a_{i}}{d t}\right|_{\text {dep }} g_{i}\left(a_{i}\right)\right\} \\
&\left.\frac{\partial g_{\mathrm{AP} i}\left(a_{i}\right)}{\partial t}\right|_{\text {dep }}=-\frac{\partial}{\partial \ln a_{i}}\left\{\left.\frac{d \ln a_{i}}{d t}\right|_{\text {dep }} g_{\mathrm{AP} i}\left(a_{i}\right)\right\}
\end{aligned}
$$

with

$$
\left.\frac{d \ln a_{i}}{d t}\right|_{\text {dep }}=\left.\left.\frac{1}{a_{i}} \frac{d a_{i}}{d m_{i}}\right|_{\text {dep }} \frac{d m_{i}\left(a_{i}\right)}{d t}\right|_{\text {dep }} .
$$

Following Hall and Pruppacher (1976) [their Eqs. (34) and (35)] the vapor mass acquired by a snow crystal was deposited such that the relationship between the thickness $h_{i}$ and the diameter $d_{i}$ of the unrimed planar snow crystals followed Auer and Veal (1970) according to

$$
h_{i}=0.01263 d_{i}^{0.449}
$$

where $h_{i}$ and $d_{i}$ are given in $\mathrm{cm}$. Together with Eq. (35) we determined

$$
\left.\frac{d a_{i}}{d m_{i}}\right|_{\text {dep }}=\left(\frac{\partial m_{i}}{\partial h} \frac{\partial h}{\partial a_{i}}+\frac{\partial m_{i}}{\partial a_{i}}\right)^{-1} .
$$

Once the snow crystals have reached a size which allows them to collide with supercooled drops with finite collision efficiency they were assumed to begin to grow by riming while continuing to grow by diffusion of water vapor. Thereby, as mentioned above, the attachment of supercooled drops was assumed to take place only on the ice crystal's basal planes and not on the sides. The continued diffusional growth was assumed to proceed by preserving the relationship $\partial b_{i} /$ $\partial a_{i}=\partial h_{i} / \partial a_{i}$ according to Eq. (35), where $b_{i}$ is the thickness of the rimed snow crystal. Once the rimed snow crystals have reached a size where the axis ratio $b_{i} / a_{i}$ exceeds a value of 0.25 the ice particle was assumed to be a graupel.

The growth of the graupel by deposition of water vapor was treated analogously to Eq. (30), assuming the graupel to be spherical. Then the time rate-ofchange of the number and mass density distribution functions of graupel and mass density distribution function of aerosol particle mass in the graupel is given by

$$
\left.\frac{\partial f_{g}\left(a_{g}\right)}{\partial t}\right|_{\text {dep }}=-\frac{\partial}{\partial \ln a_{g}}\left\{\left.\frac{d \ln a_{g}}{d t}\right|_{\text {dep }} f_{g}\left(a_{g}\right)\right\}
$$

$$
\begin{aligned}
& \left.\frac{\partial g_{g}\left(a_{g}\right)}{\partial t}\right|_{\text {dep }}=\left.f_{g}\left(a_{g}\right) \frac{d m_{g}\left(a_{g}\right)}{d t}\right|_{\text {dep }} \\
& -\frac{\partial}{\partial \ln a_{g}}\left\{\left.\frac{d \ln a_{g}}{d t}\right|_{\text {dep }} g_{g}\left(a_{g}\right)\right\} \\
& \left.\frac{\partial g_{\mathrm{AP} g}\left(a_{g}\right)}{\partial t}\right|_{\text {dep }}=-\frac{\partial}{\partial \ln a_{g}}\left\{\left.\frac{d \ln a_{g}}{d t}\right|_{\text {dep }} g_{\mathrm{APg}}\left(a_{g}\right)\right\} \\
& \left.\frac{d \ln a_{g}}{d t}\right|_{\text {dep }}=\left.\left.\frac{d \ln a_{g}}{d m_{g}\left(a_{g}\right)}\right|_{\text {dep }} \frac{d m_{g}\left(a_{g}\right)}{d t}\right|_{\text {dep }}
\end{aligned}
$$

with

$$
\left.\frac{d \ln a_{g}}{d m_{g}\left(a_{g}\right)}\right|_{\text {dep }}=\frac{1}{3 m_{g}\left(a_{g}\right)}\left(\frac{\rho_{g}}{\rho_{g, \text { dep }}}\right)^{1 / 3} .
$$

For these computations we have assumed the density of the water vapor mass deposited on the graupel $\rho_{g, \text { dep }}$ $=0.2 \mathrm{~g} \mathrm{~cm}^{-3}$, accórding to Heymsfield and Pflaum (1985, Fig. 5). The density $\rho_{g}$ of the graupel was calculated from the mass of the graupel according to

$$
m_{g}\left(a_{g}\right)=\frac{g_{g}\left(a_{g}\right)}{f_{g}\left(a_{g}\right)} .
$$

The time rate-of-change of the number density distribution function for graupel due to collision of supercooled drops with the graupel we computed from

$$
\begin{aligned}
& \left.\frac{\partial f_{g}\left(a_{g}\right)}{\partial t}\right|_{g, \text { rim }}=-\frac{\partial}{\partial \ln a_{g}}\left\{\left.\frac{d \ln a_{g}}{d t}\right|_{g, \text { rim }} f_{g}\left(a_{g}\right)\right\} \\
& \left.\frac{d \ln a_{g}}{d t}\right|_{g, \text { rim }}=\left.\left.\frac{d \ln a_{g}}{d m_{g}\left(a_{g}\right)}\right|_{g, \text { rim }} \frac{d m_{g}\left(a_{g}\right)}{d t}\right|_{g, \text { rim }} \\
& \left.\frac{d \ln a_{g}}{d m_{g}\left(a_{g}\right)}\right|_{g, \text { rim }}=\frac{1}{3 m_{g}\left(a_{g}\right)}\left(\frac{\rho_{g}}{\rho_{g, \text { accr }}}\right)^{1 / 3} \\
& \left.\frac{d m_{g}\left(a_{g}\right)}{d t}\right|_{g, \text { rim }}=\int_{0}^{\infty} m f_{d}(m) K_{g}\left(a_{g}, a(m)\right) d m .
\end{aligned}
$$

The density $\rho_{g, \text { accr }}$ of the rime deposited by attachment of supercooled drops on the graupel was computed following the scheme by Heymsfield and Pflaum (1985) where

$$
\rho_{g, \text { accr }}\left(a_{g}\right)=\left\{\begin{array}{l}
0.30 \psi^{0.44} \\
T_{g} \leqslant-5^{\circ} \mathrm{C} \\
0.30 \psi^{0.44}, \\
T_{g}>-5^{\circ} \mathrm{C} \text { and } \psi<1.60 \\
e^{-0.03115-1.7030 \psi+0.9116 \psi^{2}-0.1224 \psi^{3}} \\
T_{g}>-5^{\circ} \mathrm{C} \text { and } \psi \geqslant 1.60
\end{array}\right.
$$

with

$$
\psi=-\frac{\bar{a} u_{\text {impact }}\left(a_{g}, \bar{a}\right)}{T_{g}\left(a_{g}\right)}
$$


in which the surface temperature $T_{g}\left(a_{g}\right)$ of the graupel was computed analogously to the surface temperature of snow crystals growing by diffusion of water vapor (Hall and Pruppacher 1978). The radial impact velocity $u_{\text {impact }}$ was calculated using the parameterization scheme of Rasmussen and Heymsfield (1985).

The time rate of change of the mass density distribution functions for graupel, snow crystals, and aerosol particle mass in the graupel and snow crystals, respectively, is found from

$\left.\frac{\partial g_{i}\left(a_{i}\right)}{\partial t}\right|_{i, \text { rim }}=f_{i}\left(a_{i}\right) \int_{0}^{\infty} m f_{d}(m) K_{i}\left(a_{i}, a(m)\right) d m$

$\left.\frac{\partial g_{\mathrm{AP} i}\left(a_{i}\right)}{\partial t}\right|_{i, \mathrm{rim}}=f_{i}\left(a_{i}\right) \int_{0}^{\infty} g_{\mathrm{AP} d}(m) K_{i}\left(a_{i}, a(m)\right) d m$

$$
\begin{aligned}
\left.\frac{\partial g_{g}\left(a_{g}\right)}{\partial t}\right|_{g, \mathrm{rim}} & =f_{g}\left(a_{g}\right) \int_{0}^{\infty} m f_{d}(m) K_{g}\left(a_{g}, a(m)\right) \\
& \times d m-\frac{\partial}{\partial \ln a_{g}}\left\{\left.\frac{d \ln a_{g}}{d t}\right|_{g, \text { rim }} g_{g}\left(a_{g}\right)\right\}
\end{aligned}
$$

$$
\begin{gathered}
\left.\frac{\partial g_{\mathrm{APg}}\left(a_{g}\right)}{\partial t}\right|_{g, \text { rim }}=f_{g}\left(a_{g}\right) \int_{0}^{\infty} g_{\mathrm{APd} d}(m) K_{g}\left(a_{g}, a(m)\right) \\
\times d m-\frac{\partial}{\partial \ln a_{g}}\left\{\left.\frac{d \ln a_{g}}{d t}\right|_{g, \text { rim }} g_{\mathrm{APg}}(a)\right\} .
\end{gathered}
$$

The time rate of change of the number and mass density distribution functions of snow crystals and graupel due to impaction of aerosol particles was computed analogously to the collision of supercooled drops on the particles; i.e. $\left.\left\{\left[\partial f_{g}\left(a_{g}\right)\right] / \partial t\right\}\right|_{\mathrm{AP}, \text { coll, } g}$ from Eqs. (43)-(46) where $K_{g, \mathrm{AP}}\left(a_{g}, r_{\mathrm{AP}}\right)$ now replaces $K_{g}\left(a_{g}\right.$, $a),\left.\left\{\left[\partial g_{i}\left(a_{i}\right)\right] / \partial t\right\}\right|_{\mathrm{AP}, \text { coll }, i}$ from Eq. (49) where $K_{i, \mathrm{AP}}\left(a_{i}\right.$, $\left.r_{\mathrm{AP}}\right)$ replaces $K_{i}\left(a_{i}, a\right),\left.\left\{\left[\partial g_{\mathrm{AP} i}\left(a_{i}\right)\right] / \partial t\right\}\right|_{\mathrm{AP}, \text { coll }, i}$ from Eq. $(50)$ where $K_{i, \mathrm{AP}}\left(a_{i}, r_{\mathrm{AP}}\right)$ replaces $K_{i}\left(a_{i}, a\right)$, $\left.\left\{\left[\partial g_{g}\left(a_{g}\right)\right] / \partial t\right\}\right|_{\mathrm{AP}, \text { coll }, g}$ from Eq. (51) where $K_{g, \mathrm{AP}}\left(a_{g}\right.$, $\left.r_{\mathrm{AP}}\right)$ replaces $K_{g}\left(a_{g}, a\right)$, and $\left.\left\{\left[\partial g_{\mathrm{APg}}\left(a_{g}\right)\right] / \partial t\right\}\right|_{\mathrm{AP}, \text { coll }, g}$ from Eq. (52) where $K_{g, \mathrm{AP}}\left(a_{g}, r_{\mathrm{AP}}\right)$ replaces $K_{g}\left(a_{g}, a\right)$.

The time rate of change of the number and mass density distribution functions of the snow crystals and graupel due to densely rimed snow crystals converting to graupel were computed from the relations

$$
\begin{gathered}
\left.\frac{\partial f_{g}\left(a_{g}=a_{i}\right)}{\partial t}\right|_{\mathrm{conv}}=-\left.\frac{\partial f_{i}\left(a_{i}\right)}{\partial t}\right|_{\text {conv }} \\
\left.\frac{\partial g_{g}\left(a_{g}=a_{i}\right)}{\partial t}\right|_{\mathrm{conv}}=-\left.\frac{\partial g_{i}\left(a_{i}\right)}{\partial t}\right|_{\mathrm{conv}} \\
\left.\frac{\partial g_{\mathrm{APg}}\left(a_{g}=a_{i}\right)}{\partial t}\right|_{\mathrm{conv}}=-\left.\frac{\partial g_{\mathrm{AP} i}\left(a_{i}\right)}{\partial t}\right|_{\mathrm{conv}} \cdot
\end{gathered}
$$

\section{c. Dynamic framework}

The dynamic model used for the present computations was the air-parcel model with entrainment discussed in detail by Flossmann et al. [1985, Eqs. (22)(31)]. Due to the presence of ice particles in the cloud only their Eqs. (25) - (28) and (30)-(31) remain unchanged. Equations (22)-(24) and (29), however, are now

$$
\begin{aligned}
\frac{d T}{d t}=-\frac{g U}{c_{p a}}-\mu(T- & \left.T^{\prime}\right) U+\frac{L_{e}}{c_{p a}} C_{p h, e} \\
& +\frac{L_{m}}{c_{p a}} C_{p h, m}+\frac{L_{s}}{c_{p a}} C_{p h, s}
\end{aligned}
$$

with

$$
\begin{gathered}
C_{p h, e}=\left.\frac{d w_{L}^{*}}{d t}\right|_{\text {con/eva }} \\
C_{p h, m}=\left.\frac{d w_{i}+d w_{g}}{d t}\right|_{\text {frd } / \text { rime } / \text { AP,coll }} \\
C_{p h, e}=\left.\frac{d w_{i}+d w_{g}}{d t}\right|_{\text {dep }} \\
\frac{d w_{v}}{d t}=-\mu\left(w_{v}-w_{v}^{\prime}\right) U-C_{p h, e}-C_{p h, s},
\end{gathered}
$$

and with the entrainment parameter

$$
\mu=\frac{0.5}{R_{p}} \text {. }
$$

\section{d. Initialization and boundary conditions}

As initial condition for solving the model outlined above we chose the aerosol particle-size distribution as suggested by Jaenicke (1988) for a rural background aerosol, resulting from a superposition of three lognormal distributions

$$
\begin{aligned}
f_{\mathrm{APa}}\left(\ln r_{\mathrm{AP}}, t=0\right) \\
\quad=\sum_{j=1}^{3}\left[\left(\frac{n_{j}}{\sqrt{2 \pi} \log \sigma_{j} \ln 10}\right) \exp \quad-0.5 \frac{\left(\log \frac{r_{\mathrm{AP}}}{r_{j}}\right)^{2}}{\left(\log \sigma_{j}\right)^{2}}\right]
\end{aligned}
$$

TABLE 1. Parameters to characterize the "rural background" aerosol particle distribution given in Eq. (62) after Jaenicke (1988); $n_{j}=$ total number of aerosol particles per $\mathrm{cm}^{3}, r_{j}=$ geometric mean aerosol particle radius in $\mu \mathrm{m}, \sigma_{j}=$ standard deviation in mode $j$.

\begin{tabular}{crcc}
\hline Mode $j$ & $n_{j}$ & $r_{j}$ & $\log \sigma_{j}$ \\
\hline 1 & 6650 & 0.00739 & 0.225 \\
2 & 147 & 0.02690 & 0.557 \\
3 & 1990 & 0.04190 & 0.266 \\
\hline
\end{tabular}



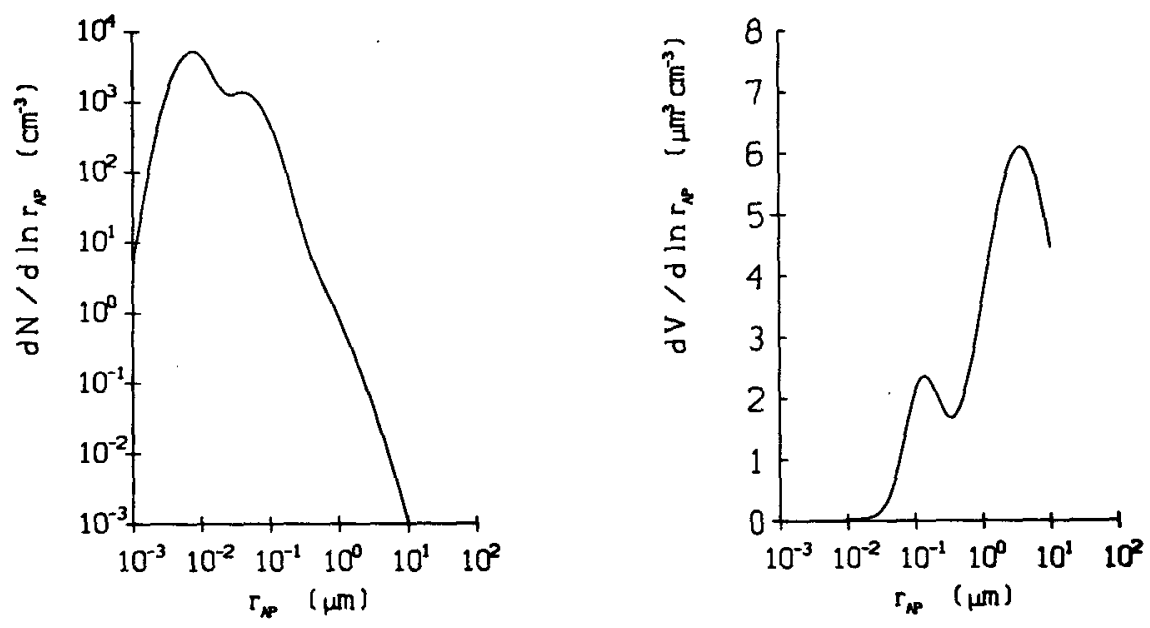

FIG. 1. Number (left-hand side) and volume (right-hand side) distribution of aerosol particles after Jaenicke (1988) [see Eq. (62) and Table 1]; total number of particles $=8786 \mathrm{~cm}^{-3}$, total aerosol particle mass $=28.17 \mu \mathrm{g} \mathrm{m}^{-3}$.

with $n_{j}, r_{j}$ and $\log \sigma_{j}$ given in Table 1 as the starting condition at cloud base. The distribution is plotted in Fig. 1. The aerosol particles were assumed to consist of either $50 \%$ or $15 \%$ water-soluble material; i.e. $\epsilon$ $=0.5$ or $\epsilon=0.15$, where $\epsilon=m_{s} / m_{\mathrm{AP}}$. The aerosol composition $\epsilon=0.5$ represents a typical value for aerosol particles over Europe, while the composition $\epsilon$ $=0.15$ represents a value measured by Hobbs et al. (1985, Table 1) over the High Plains in the United States. To take into account the decrease of aerosol particle number concentrations with height in the environmental air we assumed

$$
f_{\mathrm{APa}}^{\prime}\left(\ln r_{\mathrm{AP}}, Z\right)=f_{\mathrm{APa}}\left(\ln r_{\mathrm{AP}}, t=0\right) e^{-Z / H}
$$

with a vertical attenuation height of $H=3500 . \mathrm{m}$.

In the present paper we study three model cases with different initialization of the aerosol particle composition and different ice-nucleation mechanisms. In case$l$ the aerosol particles were assumed to consist of $50 \%$ of water soluble material; i.e., $\epsilon=0.5$, and ice nucleation proceeded via freezing according to Eq. (29) following the condition of Orville and Kopp (1977) with $B^{\prime}=10^{-4} \mathrm{~cm}^{-3} \mathrm{sec}^{-1}$ and $b^{\prime}=0.66$. In case- 2 the aerosol particles consisted of $15 \%$ of water-soluble substance $(\epsilon=0.15)$ while the ice-nucleation mechanism remained the same as in case-1. In case- 3 we chose the ice nucleation to proceed according to Eq. (25), and the aerosol particles were set to consist of $50 \%$ of soluble material $(\epsilon=0.5)$, as in case- 1 .

The air parcel was assumed to start with an initial updraft speed of $1 \mathrm{~m} \mathrm{~s}^{-1}$ at an altitude of $750 \mathrm{~m}$ above ground at a temperature of $6^{\circ} \mathrm{C}$, water saturation and a pressure of $925 \mathrm{hPa}$. The vertical temperature and humidity distribution in the atmosphere was that measured at Essen (FRG) on 17 April 1986 at 0000 UTC (see Fig. 2). On this day graupel and rain showers were observed in Central Europe.

\section{Results}

In Fig. 3a-c (case-1) we have plotted the change in time during the parcel's ascent of the drop mass-, snow crystal mass-, graupel mass-distribution function, and of the distribution functions of the aerosol mass in the cloud water, in the snow crystal mass and in the graupel mass for the case that the aerosol particle distribution on which drops were nucleated had a solubility of $\epsilon$ $=0.5$, and for the case that ice nucleation proceeded via drop freezing [Eq. (29)].

Figure 3a (left-hand side) shows that most of the cloud-water mass remains in the small drops and that collision-coalescence shifts the spectrum only a little, with small precipitation-sized drops developing only very late during the model computation. Accordingly, the main mass of the aerosol captured by nucleation scavenging remains confined to the small drops (Fig. 3a, right-hand side).

Figure $3 b$ (left-hand side) and Table 2 (line 1) show

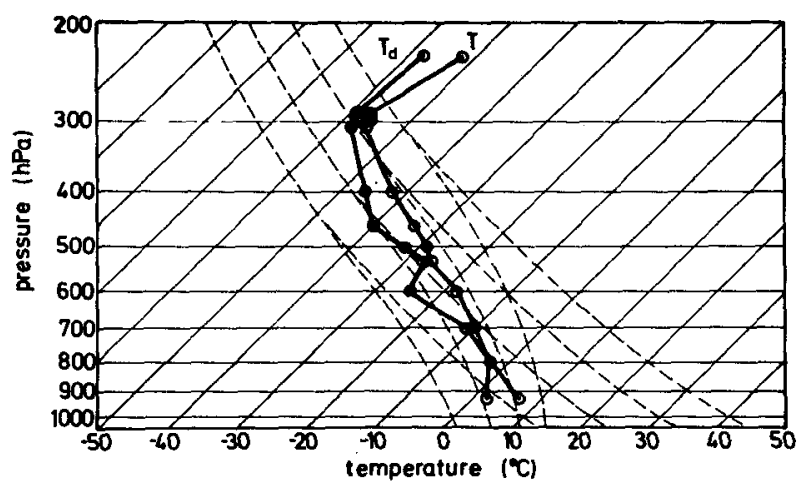

FIG. 2. Vertical temperature and humidity distribution on 17 April 1986, 00 UTC over Essen (FRG). Temperature and pressure at cloud base $6^{\circ} \mathrm{C}$ and $925 \mathrm{hPa}$, respectively. 

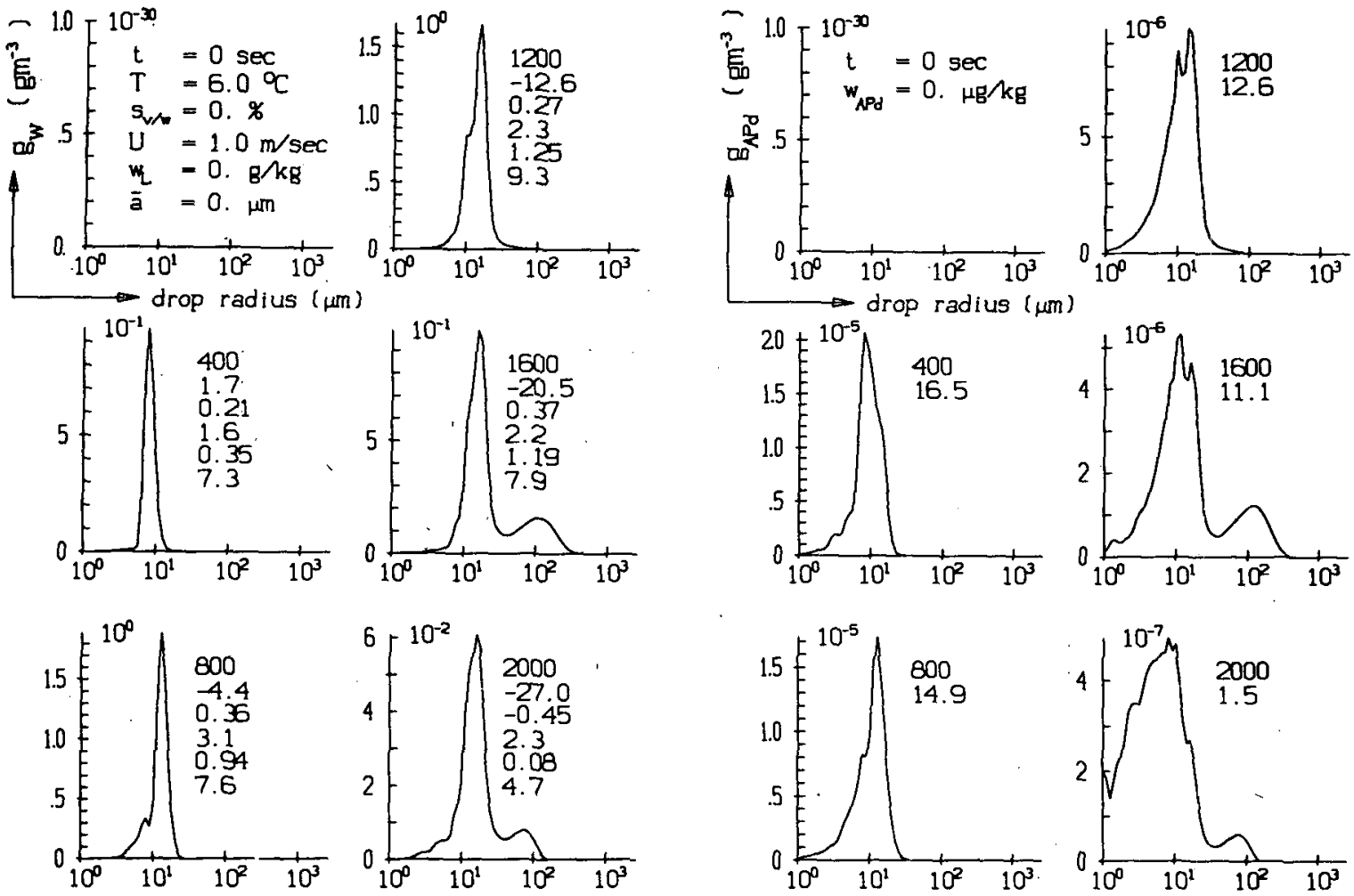

FIG. 3a. Evolution in time of the mass distribution function $g_{w}$ of the cloud water mass (left-hand side) and of the distribution function $g_{\mathrm{APd} d}$ of the aerosol mass in the cloud water (right-hand side); for ice nucleation via drop freezing according to Eq. (29) with $B^{\prime}=10^{-4} \mathrm{~cm}^{-3} \mathrm{sec}^{-1}$ and $b^{\prime}=0.66$, and for $\epsilon=0.5($ case- $I)$.
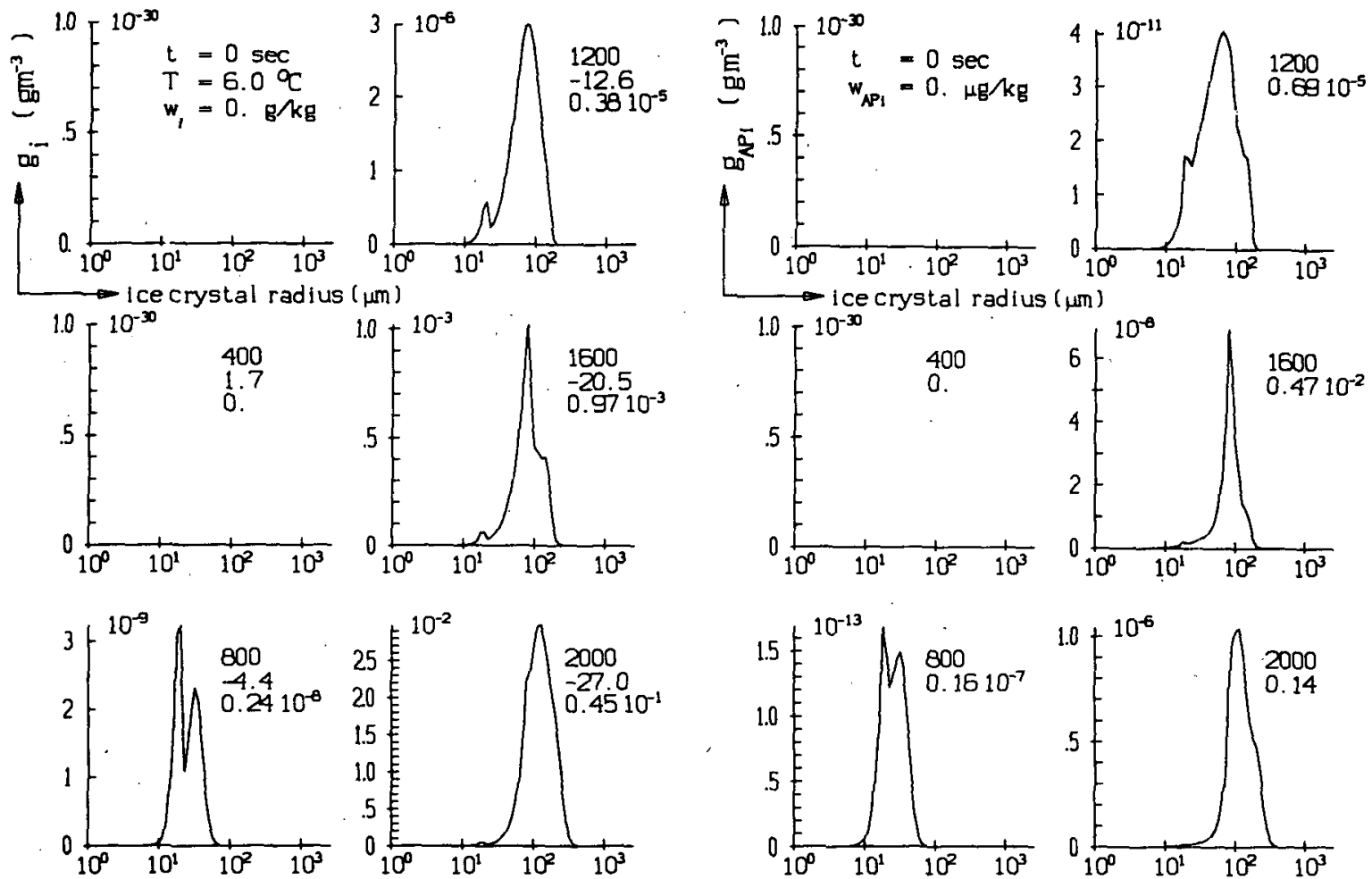

FIG. 3b. Evolution in time of the snow crystal mass distribution function $g_{i}$ (left-hand side) and of the distribution function $g_{\mathrm{AP} i}$ of the aerosol mass in the snow crystals (right-hand side) for the conditions in Fig. 3a. 

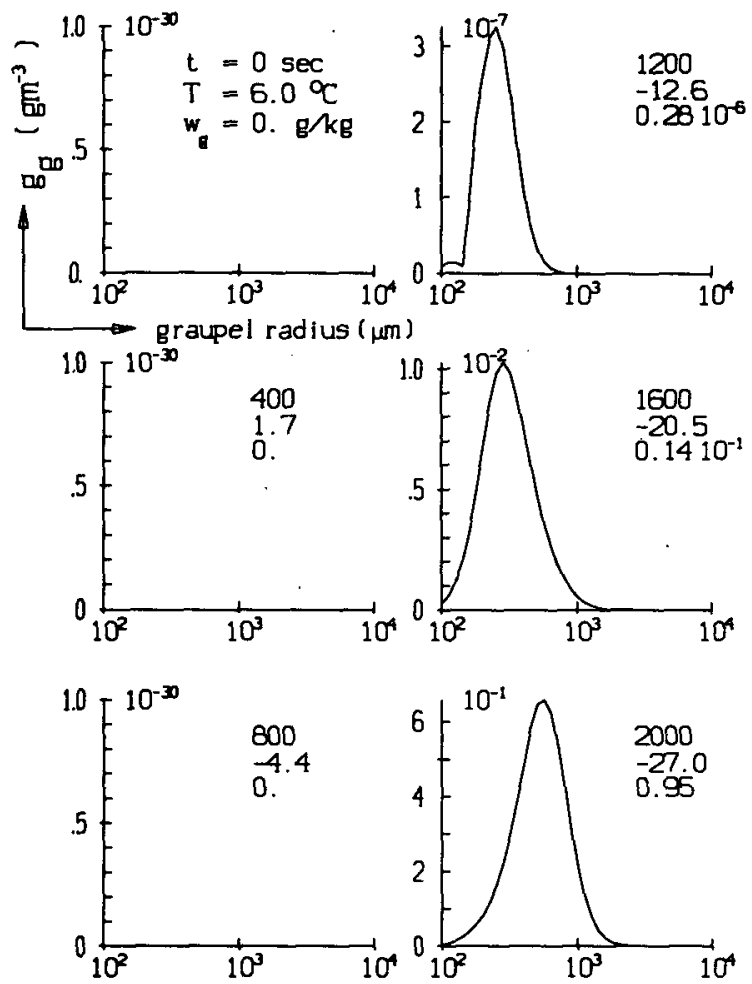
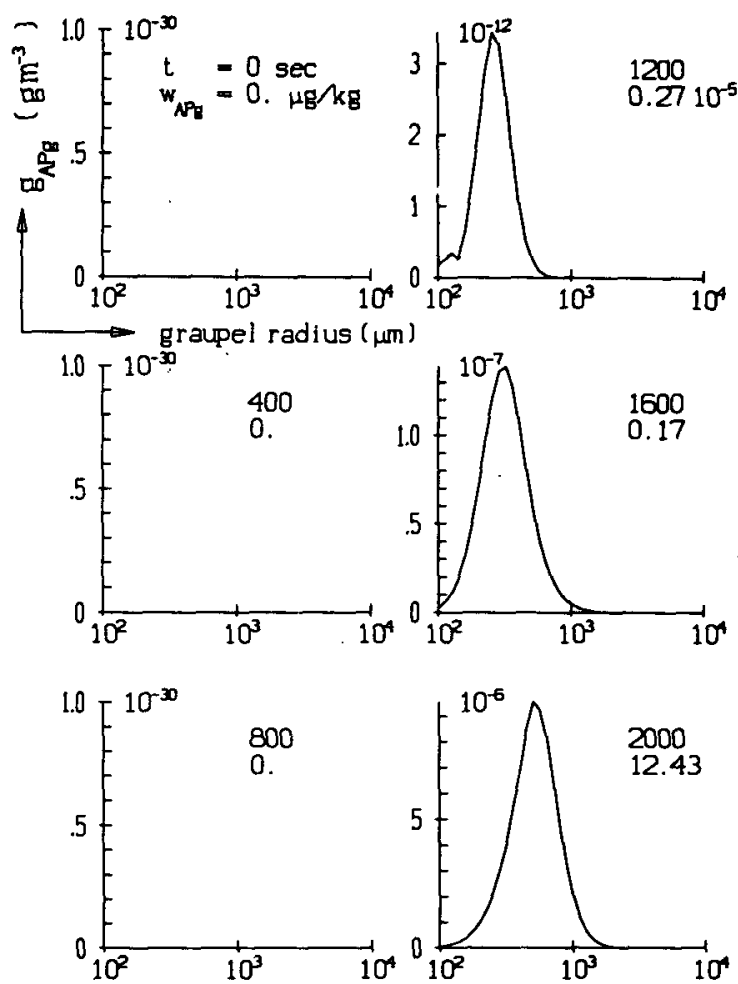

FIG. 3c. Evolution in time of the graupel mass distribution function $g_{g}$ (left-hand side) and of the distribution function $g_{A P_{g}}$ of the aerosol mass in the graupel (right-hand side) for the conditions in Fig. 3a.

that noticeable numbers of snow crystals develop after about 1200 model seconds. This is explicitly shown in Table 2 where we have listed the total number concentration of snow crystals and of graupel as a function of model time, and for the three different cases studied. With the onset of collision and coalescence at about 1200 model seconds a double maximum appears in the distribution of the snow crystals due to the fact that by that time the larger drops freeze more efficiently than the smaller ones. Subsequent growth of the snow crystals by vapor diffusion and riming shifts the dominant maximum to even larger sizes. From Fig. 3b (right-hand side) we notice that the main aerosol mass scavenged by the snow crystals is associated with the main snow crystal mass. This behavior is analogous to the behavior of all-water clouds where the main aerosol mass was found to be associated with the main water mass (Flossmann et al. 1985). Details on the behavior of the different scavenging mechanisms in mixed icewater clouds will be discussed later together with Figs. 6 to 8 .

Figure $3 \mathrm{c}$ (left-hand side) illustrates the evolution in time of the mass density distribution function of the graupel. We notice from this figure and Table 2 (line 2 ) that very few graupel develop before 1200 model seconds. However, after this time the concentration of graupel increases rapidly and, after 1600 model seconds, is further increased due to drops larger than 100 $\mu \mathrm{m}$ which had formed by collision and coalescence and had frozen by that time: Figure $3 \mathrm{c}$ (right-hand side) shows that the main aerosol mass scavenger by graupel is associated with the main graupel mass, as was found for the snow crystal mass.

It is further noteworthy from Fig. 3a (left-hand side) that at 2000 model seconds the cloud air had become subsaturated with respect to water because of the high number concentration of ice particles $\left(\sim 100 l^{-1}\right)$ which had consumed substantial amounts of water vapor. This induced that no new drops become nucleated and that the drop-size spectrum shrank due to drop evaporation (Fig. 3a).

In Figs. 4a-c and Table 2 (case-2) we have illustrated the change in time of the same parameters as in case-

TABLE 2. Total number of snow crystals and of graupel per unit volume at selected model times, and for cases 1,2 and 3 corresponding to Figs. 3, 4 and 5, respectively.

\begin{tabular}{ccccc}
\hline Case & $800 \mathrm{sec}$ & $1200 \mathrm{sec}$ & $1600 \mathrm{sec}$ & $2000 \mathrm{sec}$ \\
\hline $1: N_{i}$ & $1.1 \cdot 10^{-4}$ & $3.4 \cdot 10^{-2}$ & 5 & 83 \\
$1: N_{g}$ & 0 & $2 \cdot 10^{-5}$ & 0.5 & 16 \\
$2: N_{i}$ & $0.95 \cdot 10^{-4}$ & $2.8 \cdot 10^{-2}$ & 2.3 & 72 \\
$2: N_{g}$ & 0 & $8 \cdot 10^{-5}$ & 1.4 & 11 \\
$3: N_{i}$ & 0.02 & 0.09 & 0.13 & 0.18 \\
$3: N_{g}$ & 0 & $4 \cdot 10^{-3}$ & 0.06 & 0.08 \\
\hline
\end{tabular}



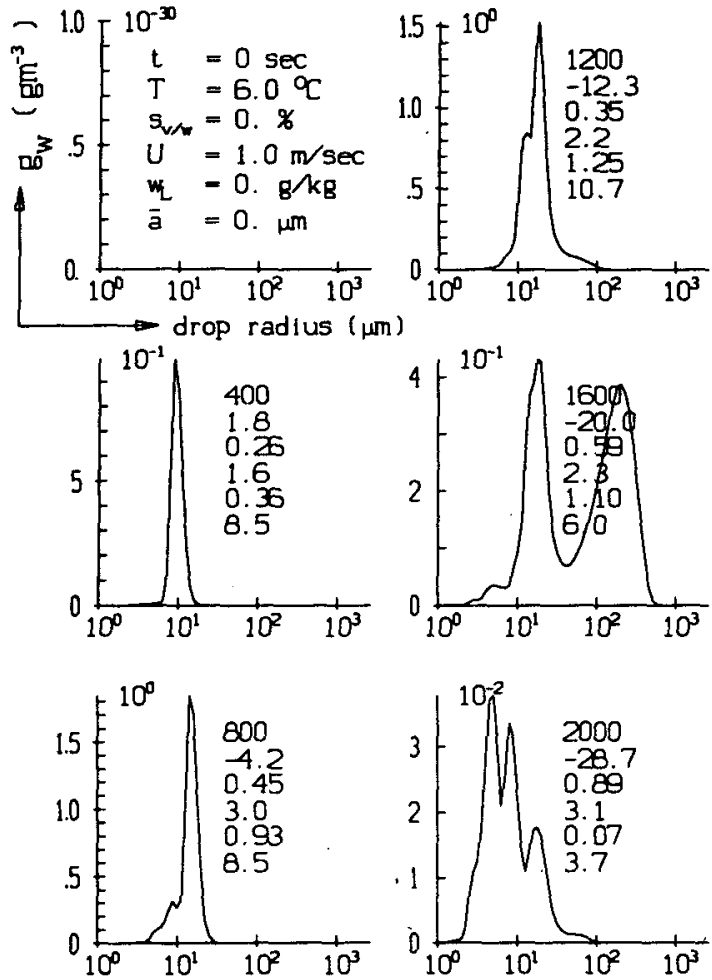
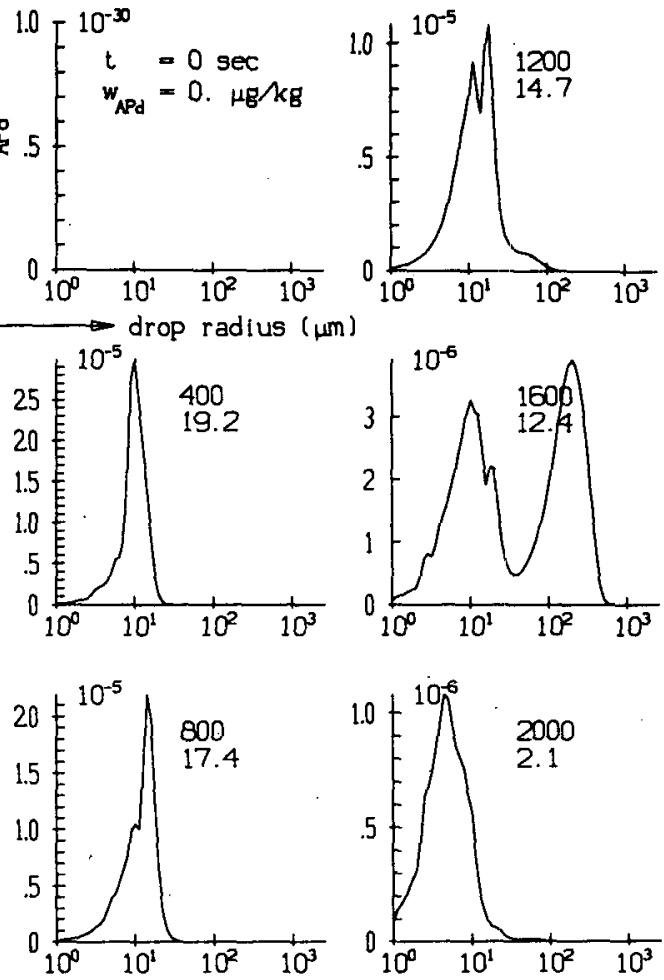

FIG. 4a. Evolution in time of the mass distribution function $g_{w}$ of the cloud water mass (left-hand side) and of the distribution function $g_{\mathrm{APd}}$ of the aerosol mass in the cloud water (right-hand side) for the conditions in Fig. 3a, but for $\epsilon=0.15$ (case-2).
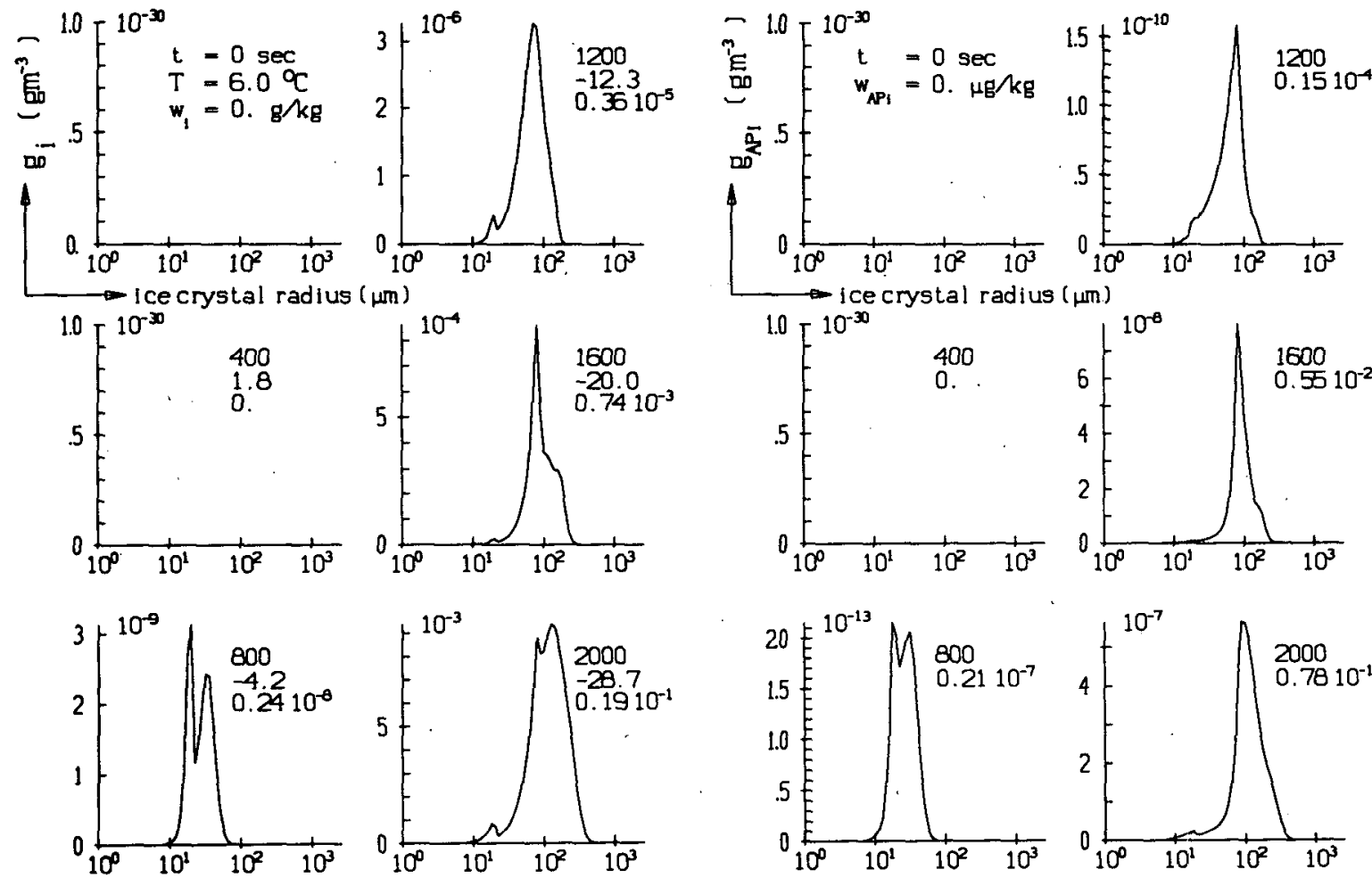

$1.0+10^{-30}$
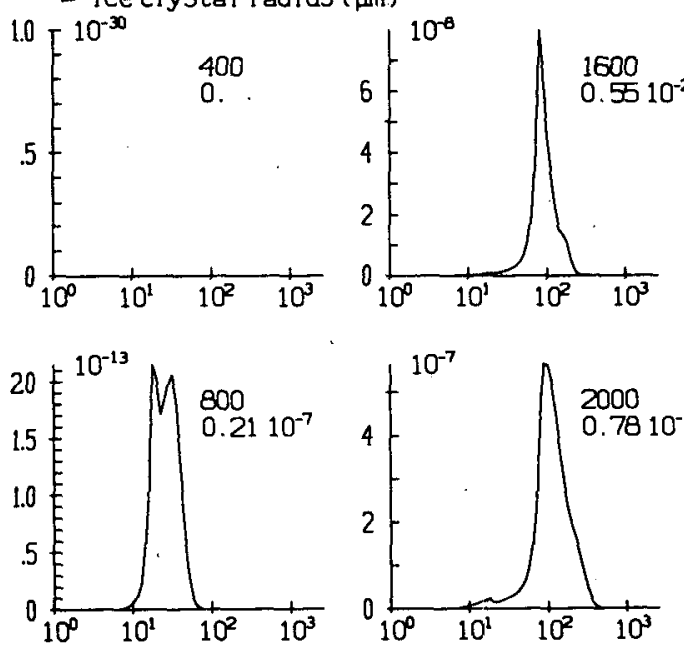

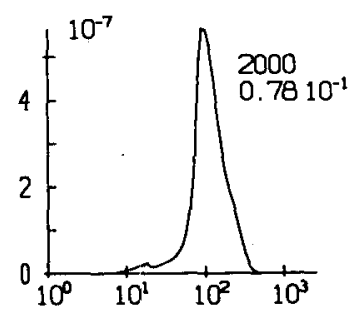

FIG. 4b. Evolution in time of the snow crystal mass distribution function $g_{i}$ (left-hand side) and of the distribution function $g_{A P i}$ of the aerosol mass in the snow crystals (right-hand side) for the conditions in Fig. 4a. 

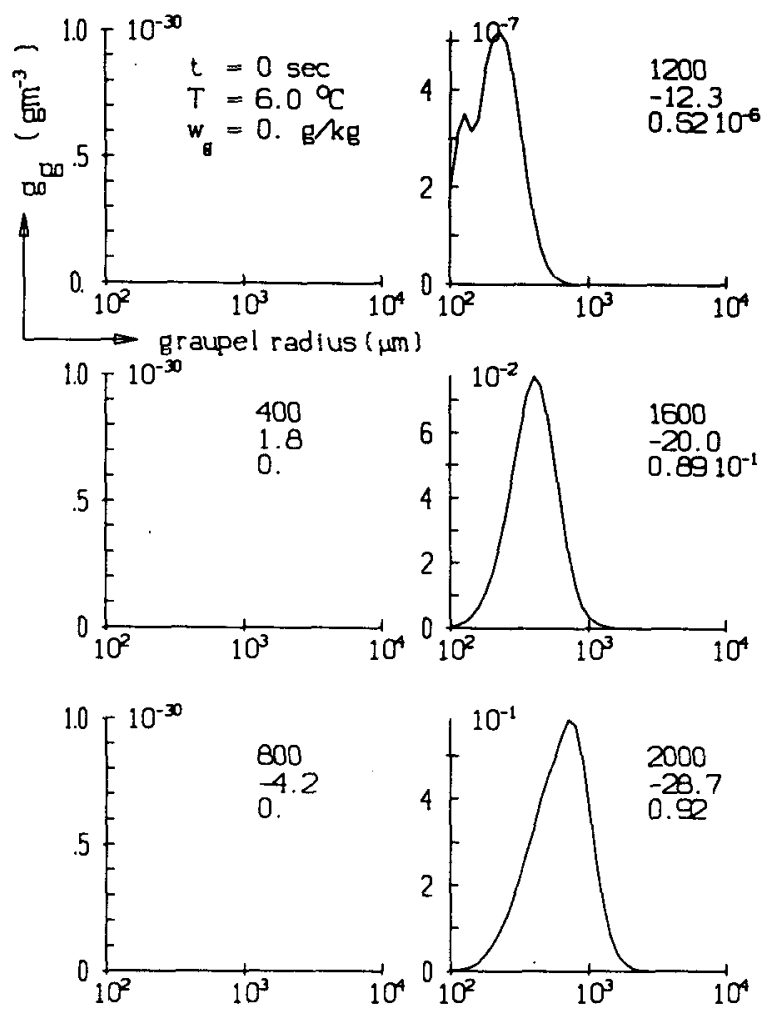
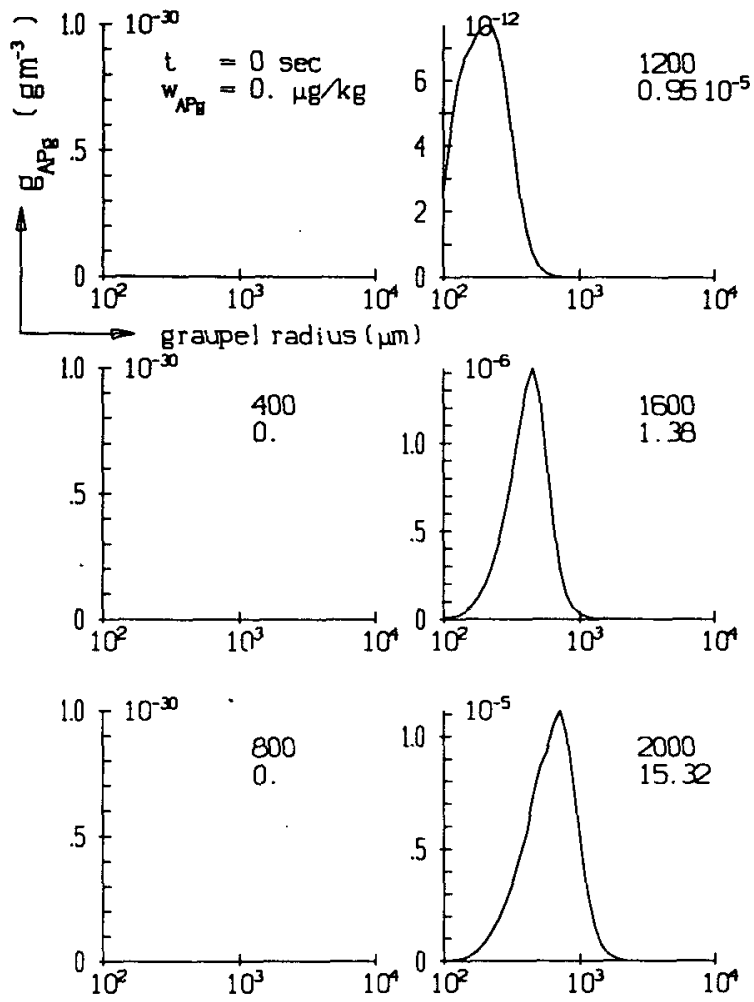

FIG. 4 c. Evolution in time of the graupel mass distribution function $g_{g}$ (left-hand side) and of the distribution function $g_{\mathrm{APg}}$ of the aerosol mass in the graupel (right-hand side) for the conditions in Fig. 4a.

1 with the exception that the aerosol particles in the size distribution according to Eq. (62) and Table 1 had a composition given by $\epsilon=0.15$. The ice nucleation mechanism was the same as in case-1. We notice from these figures that a smaller number of drops became activated in case-2 than in case-1. This is an indirect result of the lower value of $\epsilon$. Although the number of nucleated drops was less because of the smaller $\epsilon$, their sizes were larger, allowing them to grow faster by collision and coalescence and to freeze more readily than in case-1. This in turn caused the graupel to develop earlier but in lower concentration than in case- 1 (see Table 2). This resulted in a higher vertical velocity in the cloud due to the faster latent heat release and prevented any subsaturation to occur in the cloud due to the higher water vapor supply.

With regard to the scavenging of aerosol particles the main conclusion for case-2 is the same as for caseI. Again, details on the relative behavior of the different scavenging mechanisms in mixed ice-water clouds will be discussed later together with Figs. 6 to 8 .

In Figs. $5 \mathrm{a}$ to $5 \mathrm{c}$ and Table 2 (case-3) we have plotted the change in time of the same parameters as in case$l$ with the exception that we chose ice nucleation to proceed via Eq. (25) while the composition of the aerosol particles remained $\epsilon=0.5$. Comparison with case-1 shows that this mode of ice nucleation produces somewhat more snow crystals and graupel in the be- ginning of the cloud life, but significantly fewer at later times. This results in a significantly less efficient removal of aerosol particle mass by riming of the liquid water and consequently allows a much more efficient growth of the drops by collision and coalescence. In addition, the fewer graupel grow individually to larger sizes than in case-1. With regard to the scavenging of aerosol particles, the main conclusion for case- 3 is the same as for cases 1 and 2. Again, details on the relative behavior of the different scavenging mechanisms will be discussed together with Figs. 6 to 8 .

In Figs. 6, 7 and 8 we have plotted, for the conditions specified for cases 1,2 and 3, respectively, the change in time of the total amount of aerosol particle mass scavenged by the various mechanisms in the cloud. We notice that over the whole model time in all three cases nucleation scavenging by drops ( $w_{\mathrm{AP} d \text {, nuc }}$ dominates impaction scavenging ( $w_{\mathrm{AP} d \text {,imp }}$ ) by drops as well as all other scavenging modes. With regard to case-1 and case- 2 , in which ice nucleation takes place by drop freezing, aerosol particle mass is taken up and locked in the ice phase in five different ways: (i) by impaction of aerosol particles on the formed snow crystals $w_{\mathrm{AP} i \text { imp }}$, (ii) by impaction of aerosol particles on the formed graupel, $w_{\mathrm{AP} g, \mathrm{imp}}$, (iii) by freezing of drops containing previously captured aerosol mass $w_{\mathrm{APd}}$, frd , (iv) by riming of snow crystals $w_{\mathrm{AP} i \text {,rim }}$, and ( $\mathrm{v}$ ) by riming of graupel $w_{\mathrm{APg}, \mathrm{rim}}$. We find from Fig. 6 (for case- 1 with $\epsilon$ 

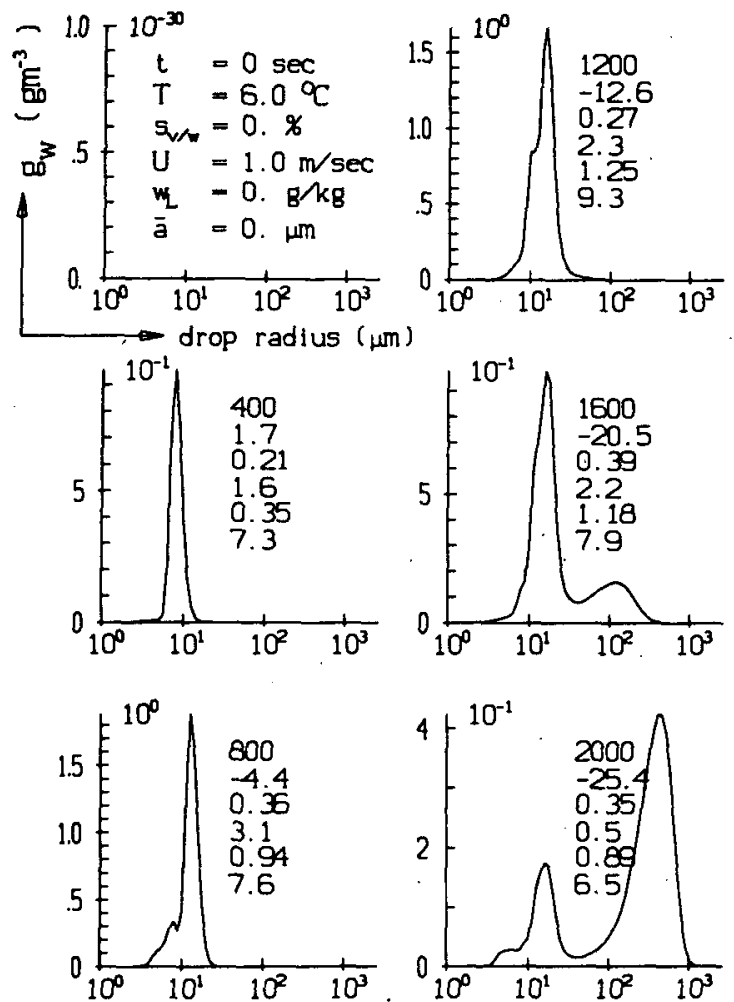
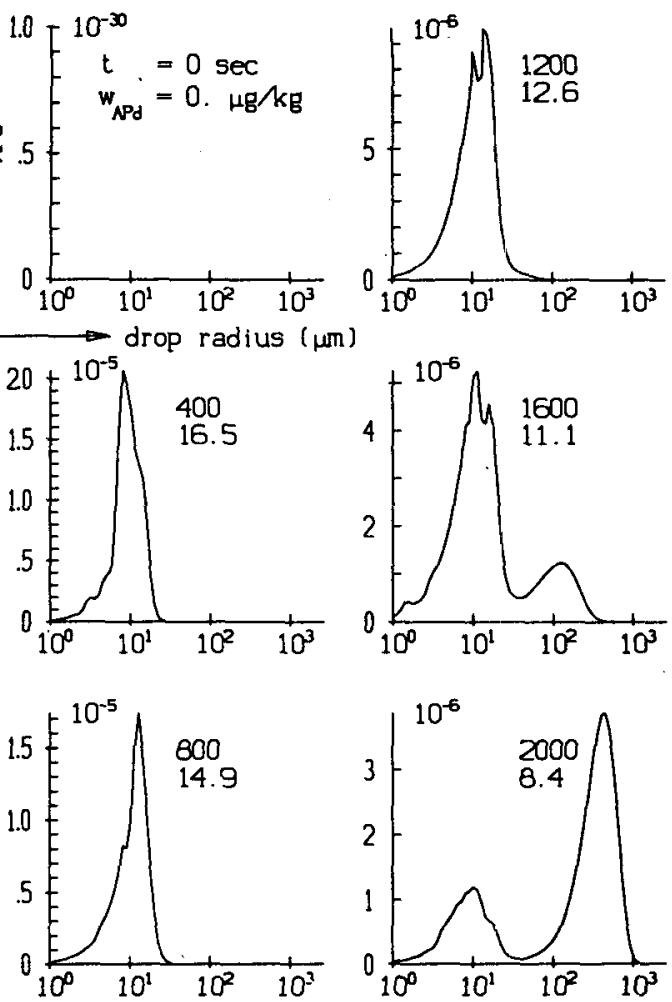

FIG. 5a. Evolution in time of the mass distribution function $g_{w}$ of the cloud water mass (left-hand side) and of the distribution function $g_{\mathrm{APd}}$ of the aerosol mass in the cloud water (right-hand side) for the conditions in Fig. 3a, but for ice nucleation via Eq. (25), and for $\epsilon=0.5$ (case-3).
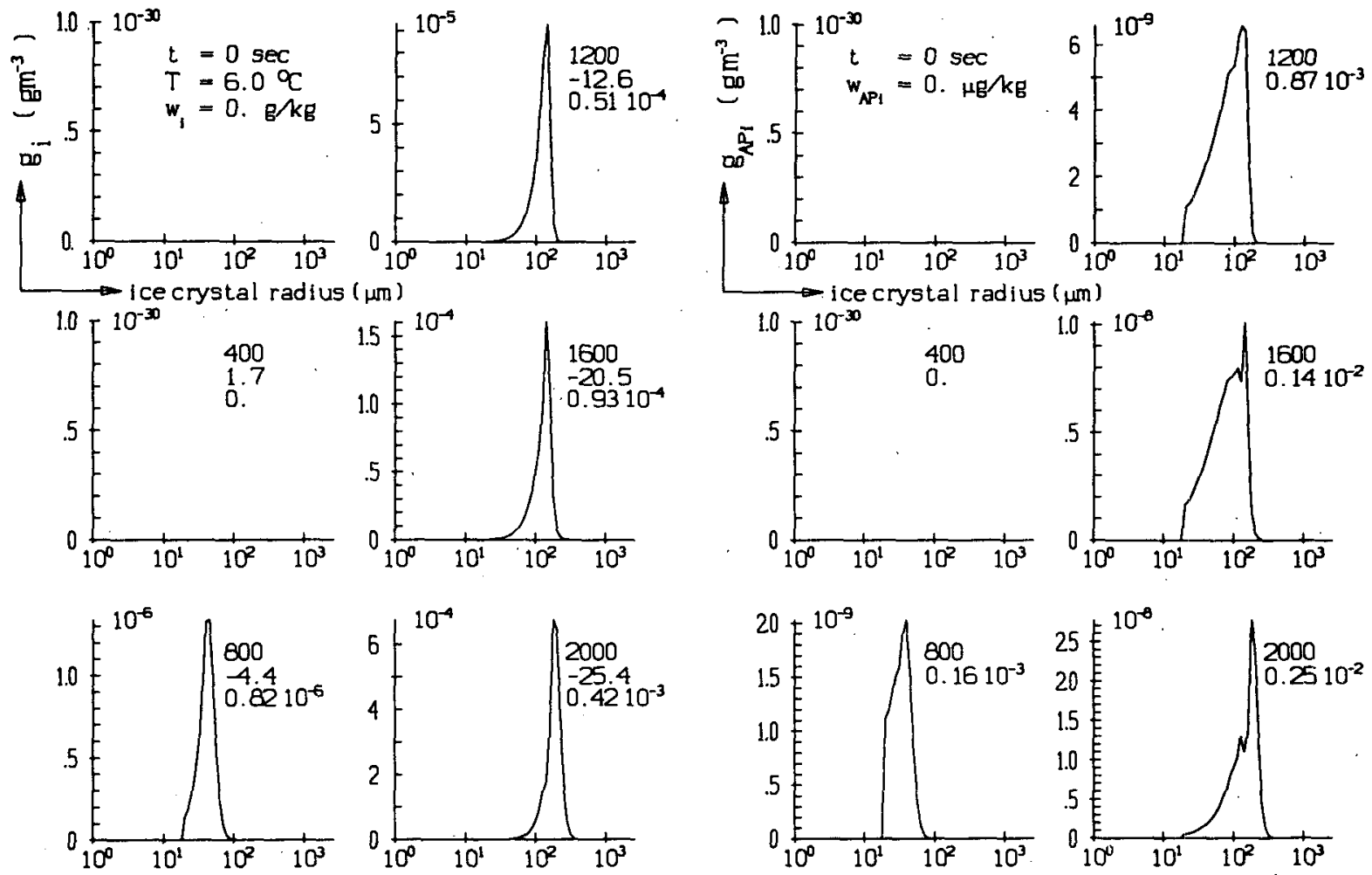

FIG. 5b. Evolution in time of the snow crystal mass distribution function $g_{i}$ (left-hand side) and of the distribution function $g_{\mathrm{AP} i}$ of the aerosol mass in the snow crystals (right-hand side) for the conditions in Fig. 5a. 

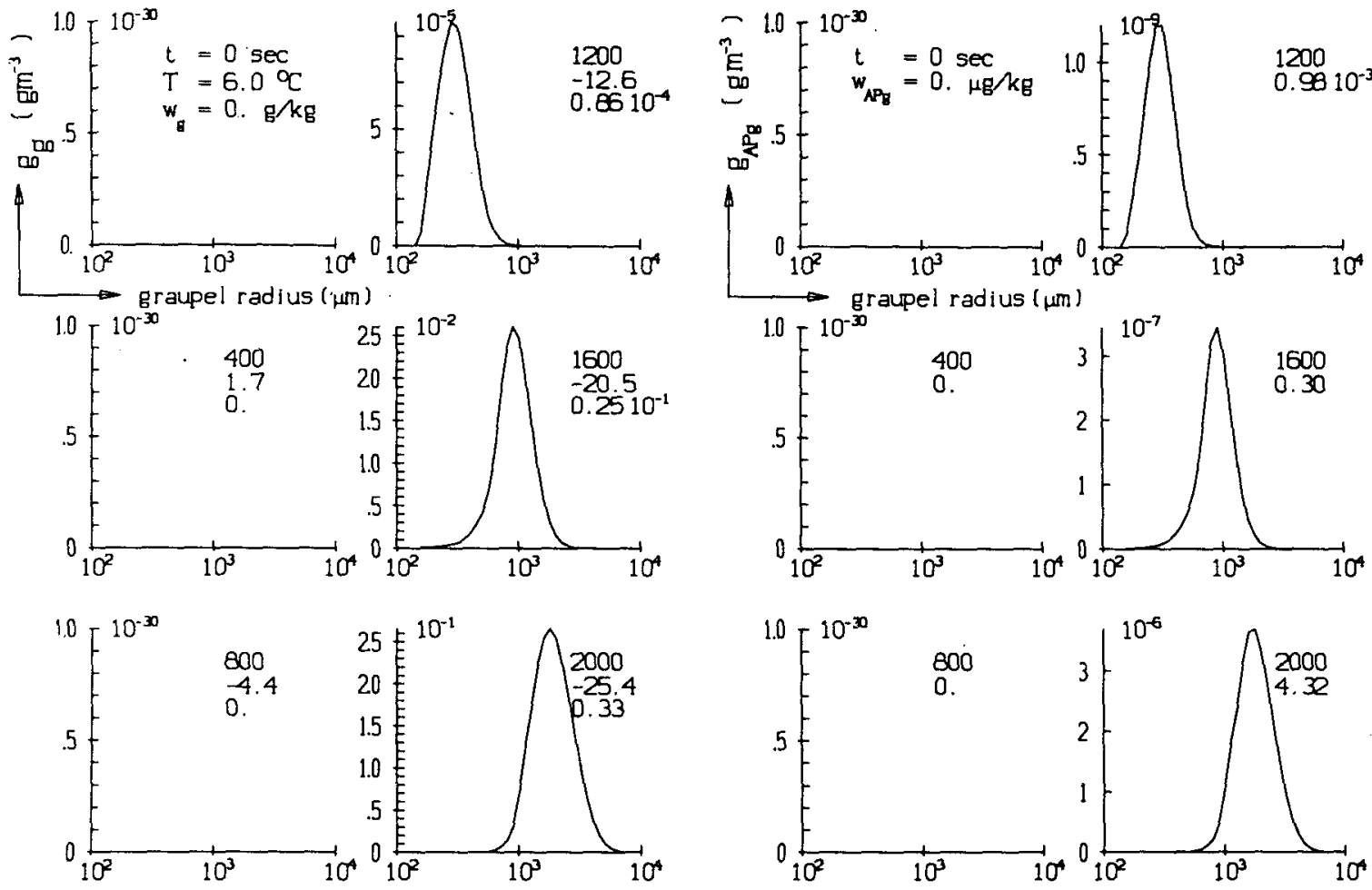

FIG. 5c. Evolution in time of the graupel mass distribution function $g_{g}$ (left-hand side) and of the distribution function $g_{\mathrm{APg}}$ of the aerosol mass in the graupel (right-hand side) for the conditions in Fig. 5a.

$=0.5)$ that, inside the cloud, impaction scavenging by ice particles ( $\left.w_{\mathrm{AP} i \text { imp }}, w_{\mathrm{APg} \text {,imp }}\right)$ starts fairly late and remains inefficient until the cloud air becomes subsa-

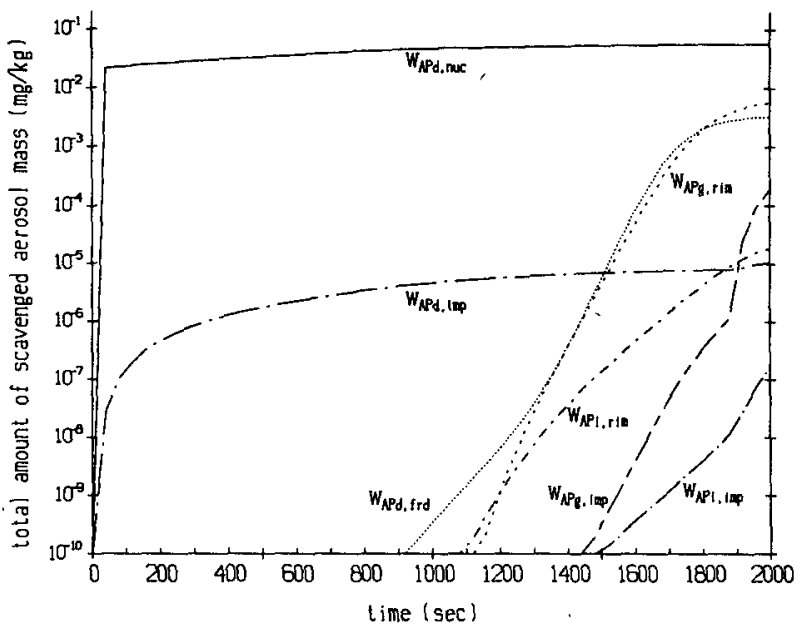

Fig. 6. Time evolution of the total amount of aerosol mass scavenged by drops via nucleation scavenging ( $\left.w_{A P d, n u c}\right)$, by graupel via riming $\left(w_{A P_{g}, r_{i}}\right)$, by ice crystals via riming $\left(w_{A P, \text { irim }}\right)$, by ice particles via drop freezing ( $\left.w_{A P d, f r d}\right)$, by drops via impaction scavenging $\left(w_{\text {APdimp }}\right)$, by graupel via impaction scavenging $\left(w_{A P, i m p}\right)$, and by ice crystals via impaction scavenging $\left(w_{A P i, j p}\right)$; for the aerosol particle distribution given by Eq. (62), for ice formation via drop freezing after Eq. (29) and for $\epsilon=0.5$. turated ( $\sim 1900$ model seconds). Transfer of aerosol mass from the liquid phase into the ice phase by drop freezing ( $w_{\mathrm{AP} d \text {, frd }}$ ), and scavenging of aerosol mass by riming of graupel $\left(w_{\mathrm{APg}, \mathrm{rim}}\right)$ dominates the scavenging of aerosol mass due to the riming of snow crystals $\left(w_{\mathrm{AP} i, \mathrm{rim}}\right)$ as well as due to the impaction on ice particles $\left(w_{\mathrm{AP} i, \mathrm{imp}}, w_{\mathrm{APg}, \mathrm{imp}}\right)$. The efficient uptake of aerosol mass by riming of graupel is due to the fact that the graupel

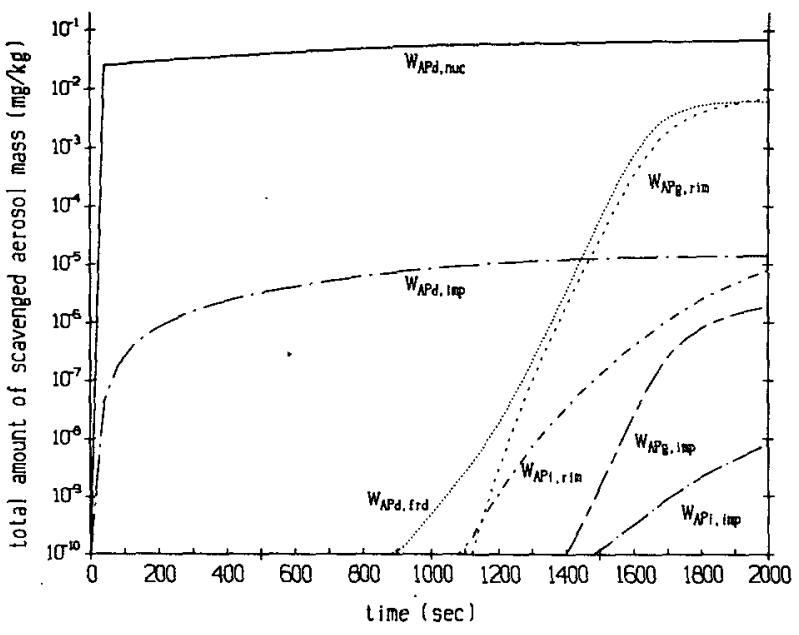

Fig. 7. As in Fig. 6, but for $\epsilon=0.15$. 


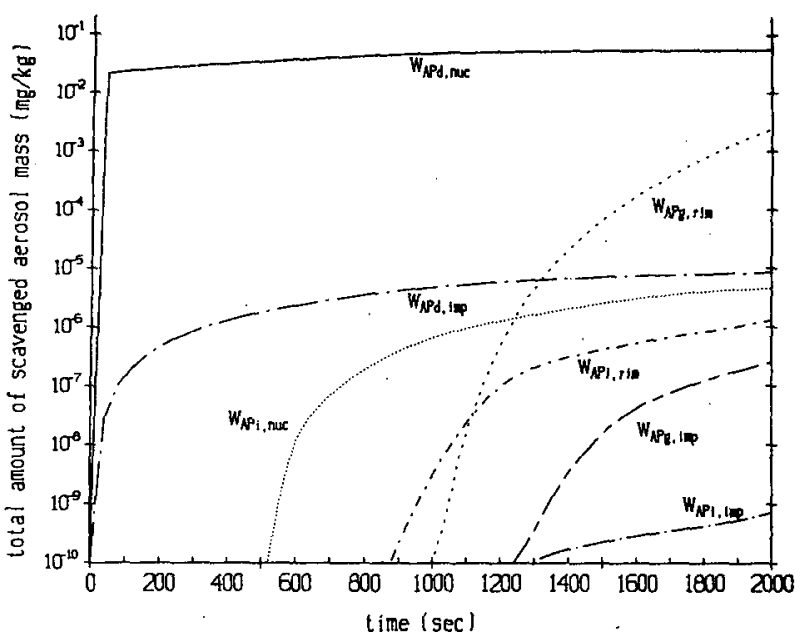

FIG. 8. As in Fig. 6, but for ice formation via Eq. (25) $\left(w_{A P i, n u c}\right)$ and $\epsilon=0.5$.

acquire drops which themselves have previously, very efficiently scavenged aerosol particles by nucleation scavenging ( $\left.w_{\mathrm{APd} d \text {,nuc }}\right)$.

In Fig. 7 we have plotted the same parameters as in Fig. 6 again as a function of model time, but for case2 with $\epsilon=0.15$. We notice that, in general, the relative behavior of the different scavenging mechanisms has not changed much, except that $w_{\mathrm{AP} i \text {,rim }}, w_{\mathrm{AP} i, \text { imp }}$ and $w_{A P g, \text { imp }}$ are now somewhat lower than for case- 1 because no subsaturation develops in the cloud so that aerosol particles may become activated to drops until the end of the model calculations.

In Fig. 8 (case-3 with $\epsilon=0.5$ ) we have plotted the same parameters as in Figs. 6 and 7 as a function of model time, however, additionally, we plotted for the case that the ice phase is not initiated via drop freezing but via Eq. (25). We notice from this figure, that the relative importance of the various mechanisms by which aerosol becomes part of the ice phase in the cloud has now changed. The pronounced increase in the number of ice nuclei with decreasing temperature produces initially a significant increase in the amount of aerosol material scavenged by snow crystals via nucleation scavenging $\left(w_{\mathrm{AP} i, \text { nuc }}\right)$. But after the time at which graupel have formed in the cloud, $w_{\mathrm{AP} i \text {,nuc }}$ remains much below $w_{\mathrm{APg} \text {,rim }}$. This is in contrast to case-1 and case-2, where $w_{\mathrm{AP} d \text {, frd }}$ is of the same order-of-magnitude as $w_{\mathrm{AP} \text {, rim }}$. We further notice that $w_{\mathrm{APi} \text {,rim }}$ and impaction scavenging of ice particles $\left(w_{\mathrm{AP} i \text { imp }}, w_{\mathrm{APg} \text {, imp }}\right)$ remain rather unimportant, as in cases 1 and 2. In fact, $w_{\mathrm{APg}, \mathrm{imp}}$ is even less than in cases 1 and 2 .

\section{Conclusion}

From the results presented above the following conclusions may be drawn for aerosol particle scavenging inside convective mixed ice-water clouds: (i) Scavenging of aerosol particles by drop nucleation domi-

nates impaction scavenging by drops as well as all other scavenging mechanisms; (ii) scavenging of aerosol particles by nucleation of snow crystals via drop freezing or any other ice nucleation mechanism dominates impaction scavenging by snow crystals; (iii) impaction scavenging by snow crystals is, for the conditions studied, the least efficient scavenging mechanism; (iv) scavenging of aerosol particles by riming of graupel is an extremely efficient process due to the large efficiency of aerosol particle scavenging by nucleation of drops and the efficient uptake of drops by graupel; ( $v$ ) the transfer of aerosol mass into the ice phase by riming of graupel and by freezing of drops dominates all other transfer mechanisms; (vi) inside mixed ice-water clouds the aerosol mass becomes redistributed in such a manner that the main aerosol mass is associated with the main, condensed water mass; i.e., it is associated with the graupel mass if riming is the dominant process of precipitation formation and is associated with the liquid water mass if collision and coalescence of drops is the dominant process of precipitation formation. This supports the conclusion of Flossmann et al. (1985) for the redistribution of aerosol mass inside a warm cloud.

Acknowledgments. This research was funded by the Ministry for Research and Technology of the Federal Republic of Germany under Project 325-40070704580 . The authors of this paper are solely responsible for its content. The authors also acknowledge with gratitude the financial support of the German National Science Foundation under Project SFB 233.

\section{APPENDIX}

\section{Definition of Terms}

$a, \bar{a}$

$a_{g}$

$a_{i}$

$b_{i}$

$b^{\prime}$

$B^{\prime}$

$C_{p a}, C_{p h, m}$ $C_{p h, s}$

$C^{*}$

$d_{i}$

$D_{v}^{*}$

$E_{g}, E_{g, \mathrm{AP}}$

$E_{i}, E_{i, \mathrm{AP}}$

$f_{d}, f_{g}, f_{i}$

$f_{\mathrm{APa}}, f_{\mathrm{APa}}^{\prime}$ drop radius, mean drop radius of distribution.

radius of graupel.

radius of snow crystal (along $a$-axis). thickness of a rimed snow crystal. parameter of the BIGG mechanism. parameter of the BIGG mechanism. specific heat of air.

rate of water mass flux from air to water, water to ice, air to ice.

electrostatic capacitance.

width of an snow crystal $=2 a_{i}$.

corrected diffusivity of water vapor in air.

collection efficiency for graupel collecting drops, aerosol particles.

collection efficiency for snow crystals collecting drops, aerosol particles.

cloud drop, graupel, snow crystal number density distribution function. aerosol particle number density distribution function in parcel air, environment. 


$f_{v, L^{*}}$
$g$
$g_{g}, g_{i}, g_{w}$
$g_{\mathrm{AP} a}, g_{\mathrm{AP} a}^{\prime}$
$g_{\mathrm{AP} d}, g_{\mathrm{AP} g}$,
$g_{\mathrm{AP} i}$
$h_{i}$
$H$
$k_{a}$
$K_{d}$
$K_{g}, K_{g, \mathrm{AP}}$
$K_{i}, K_{i, \mathrm{AP}}$
$K_{\mathrm{AP}}$
$L_{e}, L_{m}, L_{s}$
$L^{*}$
$m_{g}, m^{\prime}$
$m_{g}, m_{i}$
$m_{s}$

$m_{\mathrm{AP}}, m_{I N}$

$n_{j}$

$N_{i}$

$N_{g}$

$N_{I N}$

$N_{\mathrm{Re}}, N_{\mathrm{Re}, \mathrm{L}}$

$N_{\mathrm{Sc}}$

$P$

$r_{j}$

$r_{\mathrm{AP}}$

$R_{v}$

$R_{P}$

$s_{v / i}$

$S_{v / w}$

$t$

$T, T^{\prime}$

$T_{g}$ ventilation coefficient for snow crystals of characteristic length $L^{*}$.

magnitude of acceleration of gravity. graupel, snow crystal, liquid water mass density distribution function.

aerosol particle mass density distribution function for aerosol in parcel air, environment.

aerosol particle mass density distribution function for aerosol in cloud water, graupel, snow crystals.

thickness of an unrimed snow crystal. vertical attenuation height $=3500 \mathrm{~m}$. thermal conductivity of air.

collection kernel for drops colliding with drops.

collection kernel for graupel colliding with drops, aerosol particles.

collection kernel for snow crystals colliding with drops, aerosol particles.

collection kernel for drops colliding with aerosol particles.

latent heat of evaporation, melting, sublimation.

characteristic length of ice particle $=\Omega / P$.

mass of drop.

mass of graupel, snow crystal.

mass of water-soluble component in a dry aerosol particle.

mass of growing aerosol particle, assumed $I N=8.3776 \times 10^{-12} \mathrm{~g}$.

aerosol particle number concentration of component $j$ in the "rural background" aerosol particle distribution.

total number of snow crystals per unit volume.

total number of graupel per unit volume.

calculated Ice Nuclei concentration according to FLETCHER.

Reynolds number.

Schmidt number.

perimeter of a body.

mean geometrical radius of component $j$ in the "rural background" aerosol particle distribution.

radius of aerosol particle.

specific gas constant for water vapor.

radius of rising air parcel.

supersaturation of moist air with respect to ice.

supersaturation of moist air with respect to water.

time.

absolute parcel temperature, environmental temperature in $\mathrm{K}$.

surface temperature of graupel in ${ }^{\circ} \mathrm{C}$. melting temperature $=273.15 \mathrm{~K}$. $u_{d, \infty}, u_{g, \infty}$,

$u_{i, \infty}$

$u_{\text {impact }}$

U

V

$w_{L}, w_{L}^{*}$

$w_{g}, w_{i}$

$w_{v}, w_{v}^{\prime}$

$w_{\mathrm{AP} d}, w_{\mathrm{AP} g}$,

$w_{\mathrm{AP} i}$

$w_{\mathrm{AP} d \text {,frd }}$

$w_{\mathrm{AP} d, \mathrm{imp}}$,

$w_{\mathrm{APd}, \text { nuc }}$

$w_{\mathrm{APg}, \mathrm{imp}}$

$w_{\mathrm{APg}, \mathrm{rim}}$

$w_{\mathrm{AP} i, \mathrm{imp}}$,

$w_{\mathrm{AP} i \text {, nuc }}$,

$w_{\mathrm{AP} i \text {,rim }}$

\section{Z}

$\Delta t$

$\epsilon$

$\mu$

$\nu$

$\rho_{g}$

$\rho_{g, \text { accr }}, \rho_{g, \text { dep }}$

$\rho_{\text {sat }, i}$

$\rho_{w}$

$\sigma_{j}$

$\chi$

$\psi$

$\Omega$

$\left.\Phi\right|_{\text {act }}$

$\left.\Phi\right|_{\text {con/eva }}$

$\left.\Phi\right|_{\text {conv }}$

$\left.\Phi\right|_{\text {dep }}$

$\left.\Phi\right|_{d, \text { coal }}$

$\left.\Phi\right|_{\text {frd }}$

$\left.\Phi\right|_{g / i \text {,rime }}$ terminal fall velocity of drops, graupel, snow crystals in air.

impact velocity of drops on graupel.

updraft of the rising air parcel.

total volume of aerosol particles per unit volume.

liquid water content of drops, liquid water content of drops plus liquid water attached to unactivated aerosol particles.

solid water content of graupel, snow crystals.

mixing ratio of moist air in the parcel, environment.

aerosol particle mass content of drops, graupel, snow crystals.

cumulative amount of aerosol mass scavenged by ice particles via drop freezing.

cumulative amount of aerosol mass scavenged by drops via impaction, nucleation scavenging.

cumulative amount of aerosol mass scavenged by graupel via impaction scavenging, riming.

cumulative amount of aerosol mass scavenged by snow crystals via impaction, nucleation scavenging, riming.

height above ground level.

numerical time step $=2 \mathrm{sec}$.

composition of dry aerosol particle $=m_{s} / m_{\mathrm{AP}}$.

entrainment parameter.

kinematic viscosity of air.

density of graupel.

density of accreted rime, deposited water vapor on graupel surface.

saturation vapor density over ice.

density of water.

standard deviation of component $j$ in the "rural background" aerosol particle distribution.

$=N_{S c}^{1 / 3} \cdot N_{R e, L}^{1 / 2}$.

$=-\bar{a} u_{\text {impact }}\left(a_{g}, \bar{a}\right) / T_{g}$.

total surface of ice particle.

change due to activation of aerosol particles to drops or snow crystals.

change due to condensation and/or evaporation.

change due to conversion of densely rimed snow crystals to graupel.

change due to deposition of water vapor on ice particles.

change due to collision and coalescence of drops.

change due to drop freezing.

change due to collision of graupel or snow crystals with drops. 
$\left.\Phi\right|_{\mathrm{AP}, \text { coll }, d / g / i}$ change due to aerosol particle collection of drops, graupel or snow crystals, respective.

$\Phi$ refers to the time rate change of the number and mass density distribution functions.

\section{REFERENCES}

Auer, A. H., and D. L. Veal, 1970: The dimension of ice crystals in natural clouds. J. Atmos. Sci., 27, 919-926.

Beard, K. V., 1976: Terminal velocities and shape of cloud and precipitation drops aloft. J. Atmos. Sci., 33, 851-864.

- - and S. N. Grover, 1974: Numerical collision efficiencies for small raindrops colliding with micron sized particles. J. Atmos. Sci., 31, 543-550.

Bigg, E. K., 1953: The formation of atmospheric ice crystals by the freezing of droplets. Quart. J. Roy. Meteor. Soc., 79, 510-519.

Borys, R. D., P. J. Demott and E. E. Hindman, 1983: The significance of snow crystal and mountain surface riming to the removal of atmospheric trace constituents from cold clouds. Precipitation Scavenging, Dry Deposition and Resuspension, 1, Elsevier Science, 181-189.

— E. E. Hindman and P. J. Demott, 1988: The chemical fractionation of atmospheric aerosol as a result of snow crystal formation and growth. J. Atmos. Chem., 7, 213-239.

Clark, T. L., 1977: A small scale dynamic model using a terrainfollowing coordinate transformation. J. Comput. Phys., 24, 186215 .

_- 1979: Numerical simulations with a three dimensional cloud model. J. Atmos. Sci., 36, 2192-2215.

—, and R. Gall, 1982: Three dimensional numerical model simulations of air flow over mountainous terrain. A comparison with observations. Mon. Wea. Rev., 110, 766-791.

— lations in two and three spatial dimensions using anelastic in teractive grid nesting. J. Atmos. Sci., 41, 329-350.

Delmas, R., M. Briat and M. Legrand, 1982: Chemistry of south polar snow. J. Geophys. Res., 87, 4314-4318.

Easter, R. C., and J. M. Hales, 1983: Interpretation of the Oscar data for reactive gas scavenging. Precipitation Scavenging, Dry Deposition and Resuspension, 1, Elsevier Science, 649-660.

Flossmann, A. I., W. D. Hall and H. R. Pruppacher, 1985: A theoretical study of the wet removal of atmospheric pollutants. Part I: The redistribution of aerosol particles captured through nucleation and impaction scavenging by growing cloud drops. $J$. Atmos. Sci., 42, 582-606.

- H. R. Pruppacher and J. H. Topalian, 1987: A theoretical study of the wet removal of atmospheric pollutants. Part II: The uptake and redistribution of $\left(\mathrm{NH}_{4}\right)_{2} \mathrm{SO}_{4}$ particles and $\mathrm{SO}_{2}$ gas simultaneously scavenged by growing cloud drops. J. Atmos. Sci., 44, 2912-2923.

- and - 1988: A theoretical study of the wet removal of atmospheric pollutants. Part III: The uptake, redistribution and deposition of $\left(\mathrm{NH}_{4}\right)_{2} \mathrm{SO}_{4}$ particles by a convective cloud dynamic model. J. Atmos. Sci., 45, 1857-1871.

Graedel, T. E., and J. P. Franey, 1975: Field measurements of submicron aerosol washout by snow. Geophys. Res. Lett., 2, 325 328.

Grover, S. N., H. R. Pruppacher and A. E. Hamielec, 1977: A numerical determination of the efficiency with which spherical aerosol particles collide with spherical water drops due to inertial impaction and phoretic and electric forces. J. Atmos. Sci., 34, 1655-1663.

Hall, W. D., 1980: A detailed microphysical model within a twodimensional dynamic framework: Model description and preliminary results. J. Atmos. Sci., 37, 2486-2507.

— and H. R. Pruppacher, 1976: The survival of ice particles falling from cirrus clouds in subsaturated air. J. Atmos. Sci., 33, 19952006.
Hegg, D. A., S. A. Rutledge and P. V. Hobbs, 1984: A numerical model for sulfur chemistry in warm-frontal rainbands. J. Geophys. Res., 89, 7133-7147.

Heymsfield, A. J., 1972: Ice crystal terminal velocities. J. Atmos. Sci., 29, 1348-1357.

-, and J. C. Pflaum, 1985: A quantitative assessment of the accuracy of techniques for calculating graupel growth. J. Atmos. Sci., 42, 2264-2274.

- C. A. Knight and J. E. Dye, 1979: Ice initiations in unmixed updraft cores in NE Colorado cumulus congestus. J. Atmos. Sci., 36, 2216-2258.

Hobbs, P. V., and A. L. Rangno, 1985: Ice particle concentrations in clouds. $J$. Atmos. Sci, 42, 2523-2549.

_- D. A. Bowdle and L. F. Radke, 1985: Particles in the lower troposphere over the high Plains in the US, Part I: Size distributions, chemical compositions and morphologies. J. Atmos. Sci., 42, 1344-1356.

Jaenicke, R., 1988: Aerosol Physics and Chemistry. Landolt-Boernstein Zahlenwerte und Funktionen aus Naturwissenschaften und Technik, V4b, 391-457, Springer.

Knutson, E. O., S. K. Sood and J. D. Stockham, 1976: Aerosol collection by snow and ice crystals. Atmos. Environ., 10, 395-402.

Lew, J. K., D. C. Montague, H. R. Pruppacher and R. M. Rasmussen, 1986a: A wind tunnel investigation on the riming of snowflakes Part I: Porous disks and large stellars. J. Atmos. Sci., 43, 23922409.

- - - and $-1986 \mathrm{~b}$. A wind tunnel investigation on the riming of snowflakes. Part II: Natural and synthetic aggregates. J. Atmos. Sci., 43, 2410-2417.

Locatelli, J. D., and P. V. Hobbs, 1974: Fall speeds and masses of solid precipitation particles. J. Geophys. Res., 79, 2185-2197.

Magono, C., T. Endoh, T. Harimaya and S. Kubota, 1974: A measurement of the scavenging effect of falling snow crystals on the aerosol concentration. J. Meteor. Soc. Japan, 52, 407-416.

_ F. Veno and S. Kubota, 1975a: Observations of aerosol particles attached to falling snow crystals. Part I. J. Fac. Sci., Hokkaido University Series VII, Vol. 4, No. 4

_- T. Endoh and M. Itasaka, 1975b: Observations of aerosol particles attached to falling snow crystals. Part II. J. Fac. Sci., Hok kaido University Series VII, Vol. 4, No. 4.

__, F. Veno, S. Kubota and M. Itasaha, 1979: Direct ob servations of aerosol particles attached to falling snow crystals Tellus, 31, 102-114.

Martin, J. J., P. K. Wang and H. R. Pruppacher, 1980: A theoretical determination of the efficiency with which aerosol particles are collected by simple ice crystal plates. J. Atmos. Sci., 37, 16281638.

- - - - - and R. L. Pitter, 1981: A numerical study of the effect of electric charges on the efficiencies with which planar ice crystals collect supercooled drops. J. Atmos. Sci., 38, 24622469.

Molenkamp, C. R., 1983: A scavenging model for stratified precipitation. Precipitation Scavenging, Dry Deposition and Resuspension, 1, Elsevier Science, 597-608.

Mayewski, P. A., and W. B. Lyons, 1983: Chemical composition of a high altitude fresh snowfall in the Ladakh Himalayas. Geophys. Res. Lett.; 10, 105-108.

Murakami, M., C. Hiramatsu and C. Magono, 1981: Observations of aerosol scavenging by falling snow crystals at two different sites of different heights. J. Meteor. Soc. Japan, 59, 763-771.

- and C. Magono, 1983: An experimental study of electrostatic effects on aerosol scavenging by snow crystals. Precipitation Scavenging, Dry Deposition and Resuspension, 1, Elsevier Science, 541-549.

_- T. Kimura, C. Magono and K. Kikuchi, 1983: Observations of precipitation scavenging for water soluble particles. J. Meteor. Soc. Japan, 61, 346-358.

- K. Kikuchi and C. Magono, 1985: Experiments on aerosol scavenging by natural snow crystals. Part I: Collection efficiency of uncharged snow crystals by submicron particles. $J$. Meteor. Soc. Japan, 63, 119-129. 
Orville, H. D., and F. J. Kopp, 1977: Numerical simulations of the history of a hailstorm. J. Atmos. Sci., 34, 1596-1618.

Pflaum, J. C., J. J. Martin and H. R. Pruppacher, 1978: A wind tunnel investigation of the hydrodynamic behaviour of growing, freely floating graupel. Quart. J., Roy. Meteor. Soc., 104, 179187.

Prodi, F., M. Caporaloni, G. Santachiara and F. Tampieri, 1981: Inertial capture of particle by obstacles in form of disk and stellar crystals. Quart. J. Roy. Meteor. Soc., 107, 699-710.

- 1983: The scavenging of submicron particles in mixed clouds: Physical mechanism and laboratory experiments. Precipitation Scavenging, Dry Deposition and Resuspension, 1, Elsevier Science, 505-515.

Pruppacher, H. R., and J. D. Klett, 1978: Microphysics of Clouds and Precipitation. D. Reidel, $714 \mathrm{pp}$.

Rasmussen, R. M., and A. J. Heymsfield, 1985: A generalized form for impact velocities used to determine graupel accretional densities. J. Atmos. Sci., 42, 2275-2279.

Raynor, G. S., and J. V. Hayes, 1983: Differential rain and snow scavenging efficiencies implied by ionic concentration differences in winter precipitation. Precipitation Scavenging, Dry Deposition and Resuspension, 1, Elsevier Science, 249-261.

Rosinski, J., G. Morgan, C. T. Nagamoto, G. Langer, G. Yamate and F. Parungo, 1980: Size distribution of inorganic and organic ice forming nuclei present in downdrafts of convective storms. Meteor. Rundschau, 33, 97-106.

Rutledge, S. A., D. A. Hegg and P. V. Hobbs, 1986: A numerical model for sulfur and nitrogen scavenging in narrow coldfrontal rainbands. J. Geophys. Res., 91, 14385-14402.

Sauter, D. P., and P. K. Wang, 1989: An experimental study of the scavenging of aerosol particles by natural snow crystals. J. Atmos. Sci., 46, 1650-1663.

Scott, B. C., 1981: Sulfate washout ratios in winter storms. J. Appl. Meteor., 20, 619-625.

- 1982a: Prediction of in-cloud conversion rates of $\mathrm{SO}_{2}$ to $\mathrm{SO}_{4}$ based upon a simple chemical and kinematic storm model. Atmos. Environ., 16, 1735-1752.

- $1982 \mathrm{~b}$ : Theoretical estimates of the scavenging coefficient for soluble aerosol particles as a function of precipitation type, rate and altitude. Atmos. Environ., 16, 1753-1762.

Sood, S. K., and M. R. Jackson, 1970: Scavenging by snow and ice crystals. Precipitation Scavenging, AEC Symposium, 121-136. (Available as CONF-7000601, Nat. Tech. Info Service, US Dept. of Commerce, Springfield VA. 22151.)

Starr, J. R., and B. J. Mason, 1966: The capture of airborne particles by water drops and simulated snow crystals. Quart. J. Roy. Meteor. Soc., 92, 490-499.

Stavitskaya, A. V., 1972: Capture of water aerosol drops by flat obstacles in the form of star-shaped crystals. Izv. Akad. Nank., Atmos. Ocean Phys., 8, 768-772.

Stein, D., and H. W. Georgii, 1983: Messung der Groessenverteilung atmosphaerischer Gefrierkerne unter Beruecksichtigung der Feuchte. Meteor. Rundschau, 36, 127-130.

Vittori, O., 1973: Scavenging of atmospheric particles by growing ice crystals. J. Atmos. Sci., 30, 321-324.

- and V. Prodi, 1967: Scavenging of atmospheric particles by ice crystals. J. Atmos. Sci., 24, 533-538.

Wang, P. K., 1985: A convective diffusion model for the scavenging of submicron aerosol particles by snow crystals of arbitrary shapes. J. Rech. Atmos., 19, 185-191.

- S. N. Grover and H. R. Pruppacher, 1978: On the effect of electric charges on the scavenging of aerosol particles by cloud and small rain drops. J. Atmos. Sci., 35, 1735-1743.

aerosol particles of radius less than $1 \mu \mathrm{m}$ are collected by columnar ice crystals. Pageoph., 118, 1090-1 108.

ficiencies with which columnar ice crystals scavenge aerosol particles. Precipitation Scavenging, Dry Deposition and Resuspension, 1, Elsevier Science, 561-571. 